\title{
Factors Influencing the Intrinsic Seismic Risk of Open Spaces in Existing Built Environments: A Systematic Review
}

\author{
Martina Russo ${ }^{1}\left(\mathbb{D}\right.$, Marco Angelosanti ${ }^{1, *}$, Gabriele Bernardini ${ }^{2} \mathbb{D}$, Laura Severi ${ }^{1}$, Enrico Quagliarini ${ }^{2} \mathbb{D}$ \\ and Edoardo Currà ${ }^{1}$ (D) \\ 1 Department of Civil, Building and Environmental Engineering (DICEA), Sapienza Università di Roma, \\ 00184 Rome, Italy; martina.russo@uniroma1.it (M.R.); laura.severi@uniroma1.it (L.S.); \\ edoardo.curra@uniroma1.it (E.C.) \\ 2 Department of Construction, Civil Engineering and Architecture (DICEA), Università Politecnica delle \\ Marche, 60121 Ancona, Italy; g.bernardini@univpm.it (G.B.); e.quagliarini@univpm.it (E.Q.) \\ * Correspondence: marco.angelosanti@uniroma1.it
}

check for updates

Citation: Russo, M.; Angelosanti, M.; Bernardini, G.; Severi, L.; Quagliarini, E.; Currà, E. Factors Influencing the Intrinsic Seismic Risk of Open Spaces in Existing Built Environments: A Systematic Review. Sustainability 2022, 14, 42. https://doi.org/ $10.3390 /$ su14010042

Academic Editor:

Mohammad Mojtahedi

Received: 19 November 2021

Accepted: 17 December 2021

Published: 21 December 2021

Publisher's Note: MDPI stays neutral with regard to jurisdictional claims in published maps and institutional affiliations.

Copyright: () 2021 by the authors Licensee MDPI, Basel, Switzerland. This article is an open access article distributed under the terms and conditions of the Creative Commons Attribution (CC BY) license (https:// creativecommons.org/licenses/by/ $4.0 /)$.

\begin{abstract}
Open spaces (OSs), such as streets, squares, and green areas, in existing built environments (BEs) are key places in disaster risk management. The seismic risk in the OSs is strictly related to BE characteristics. Scientific literature mainly focuses on extrinsic factors affecting risk, which are related to BE elements on the OSs frontier (e.g., buildings) that could cause indirect effects on the OSs. Conversely, just a few risk assessment studies consider intrinsic factors, which are related to OS elements that could suffer direct effects. Moreover, synoptic studies on such factors are still missing. Through literature-based research, the paper identifies specific factors influencing seismic risk in the OSs, focusing notably on intrinsic vulnerability. The literature review methodology includes both a systematic review from Scopus databases and a traditional bibliographic search using snowball analysis. According to the final selected papers, risk factors are classified into five categories of OS characteristics: morpho-typology; physical; construction; use and users; and context. Statistical analysis of the categories' recurrence in the final papers firstly allows current literature gaps to be defined. The results also provide a preliminary OSs risk index weighting each category in terms of such recurrences, thus representing a first useful step to support non-expert stakeholders in a preliminary assessment of priorities to define the seismic risk of Oss.
\end{abstract}

Keywords: earthquake; seismic risk assessment; risk factors; built environment; open space

\section{Introduction}

The existing built environment (BE) plays a key role in each stage of the disaster risk management process [1]. The need to reduce urban seismic risk leads to the BE as a system of buildings, infrastructures, and open spaces (OSs) (e.g., roads, parks, and squares) [2] coexisting and interacting to create vibrant urban functions. The well-being of society depends on the services provided by Bes and Oss give communities' inhabitants character and vitality, providing spaces to gather, rest, and participate in events, increasing social interaction and influencing behavior [3]. In urban fabrics, Oss correspond to the negative imprint of the building blocks and can be classified into linear spaces (LSs; e.g., streets and promenades) and areal spaces (ASs; e.g., squares, parks, parking areas), bordered by a built or open frontier [4]. Moreover, many factors influencing seismic risk in existing cities are closely related to the characteristics of the OSs.

\subsection{Towards a Seismic Risk Assessment of Open Spaces}

So far, most research has focused mainly on the performance of buildings and infrastructure $[3,5,6]$, and few studies are conducted on spaces complementary to the building footprint, which in urban areas correspond to OSs. The OSs network has a crucial role before, during, and after the disasters to satisfy survival needs, i.e., escaping, gathering 
together, and finding safety and shelter $[7,8]$. In particular, the urban street network should guarantee access to help from outside and safety paths to reach the equipped areas, shelters, and storage inside the urban fabric [9]. Therefore, these linear OSs are required to ensure an adequate functionality and level of efficiency, both in ordinary conditions and in post-disaster event phases, to manage the critical moments of an emergency. The affected population should walk towards the nearest emergency areas, hosted by areal OSs, without preventing emergency vehicles from moving conveniently [10]. In this sense, the amount and location of safe OSs available during and after a disaster become a pivotal factor that needs to be assessed $[7,11,12]$ with different contributions depending on the type of disaster and specific conditions. Following an earthquake, one of the most critical factors is the type of secondary disaster (e.g., landslides, floods, tsunamis, and fires) $[13,14]$. The EMDAT database reports the European natural and technological disasters of the last century, highlighting the correlation between primary and secondary disasters [15].

In this overview, the OSs should be investigated to provide insights for seismic risk mitigation by considering their form, their relation with the physical components of the BE (and possible earthquake-induced modifications), and the complex interaction systems of the BE and its users [16-18]. Hence, a comprehensive assessment of the seismic risk in an urban area cannot be exclusively dedicated to the study of buildings. It should be extended to the OSs and the use of public facilities (e.g., churches, schools), which can be used as temporary shelters after disastrous events $[9,12]$.

In this sense, regarding the extension of the seismic risk assessment concept from buildings risk to the OS risk, different considerations were made, starting from the division of the concept of risk into extrinsic and intrinsic risk factors [9,19-22]. Extrinsic factors relate to elements that do not directly belong to the OS itself but to its frontier, hereinafter defined as the physical (e.g., building) and non-physical (e.g., overlooks, water) boundary of the OS, which could hinder its use, causing indirect effects. Intrinsic factors are related to the elements that are part of the OS content itself, hereinafter defined as the physical space delimited by the frontiers including the infrastructural and interfering elements (e.g., paving, urban furniture, lifelines, underground cavities) which could be directly affected by disasters. Specifically, these concepts introduce the extension of the three main risk factors-hazard, exposure, and vulnerability - to the OS system.

The concept of a seismic hazard factor is based on the study of elements common to both $\mathrm{BE}$ and $\mathrm{OS}$, i.e., the seismological and seismogenic characteristics $[23,24]$ and the geological characteristics of the soils [25].

In the same way, the concept of exposure in a BE and in OSs is linked $[9,26]$ because they share the objects exposed to risk: people and goods. The expected movement in terms of people represents a crucial aspect of a seismic risk assessment procedure in the urban OS network. Furthermore, the concept of public exposure can be defined by direct and indirect elements. Direct exposure is determined by the users who, being on the road infrastructure, may suffer direct damage due to the collapse of structural elements (e.g., bridges, viaducts, tunnels, and trenches). The concept of indirect exposure is oriented to the assessment of the effects due to the earthquake after its occurrence and not at the same time $[9,20,27]$. In this perspective, all the population in a specific area must be considered as indirectly exposed to the earthquake, as they are potentially subject to damage resulting from the inefficiency of the street system [28,29].

Regarding the concept of physical seismic vulnerability, the infrastructure engineering literature [19-21] proposes a differentiation between the extrinsic vulnerability and intrinsic vulnerability of the OSs in a BE. Intrinsic vulnerability refers to elements that compose the infrastructure, e.g., the paving, substrates, embankments, technological networks, bridges, and retaining walls. Extrinsic vulnerability refers to buildings that are part of a structural aggregate or structural unit, whose collapse would damage the street itself. Both are part of the physical (or structural) vulnerability since they refer to the structural characteristics of the streets and the buildings facing them [6,30]. In this sense, urban seismic vulnerability is intended as the attitude to the physical and functional damage of OSs that depends on 
the functional organization of the systems that ensure the urban effect (current operating standards and the role of the individual physical elements in the overall functioning of the system) and their spatial organization (concentration of territorial diffusion and the relationship between systems and the physical environment) [31,32].

\subsection{Research Approach and Work Aims}

In view of the above, the present research adopts a systematic review process to explore factors influencing the intrinsic seismic risk of the OSs in the scientific literature, in line with other recent studies, which developed systematic reviews concerning the role of OSs in relation to seismic events.

Koren et al. [8] conducted a systematic review in the field of disaster management about the role of OSs pre- and post-disaster in enhancing urban resilience. Based on the review, the research also proposes a conceptual evaluation model of the urban systemcomposed of buildings, infrastructures, and OSs-to identify and evaluate its critical points. The review published by French et al. [17] focused on the emergency phase, reporting the potential of OSs during the short-term disaster response and long-term recovery needs. Among the results, the research identifies specific themes of interest to efficiently support seismic resilient OS planning and design processes. Both studies highlight the importance of including OSs in the seismic performance assessment of the urban system. Although the role of the OSs in a BE under earthquake emergency conditions is recognized, there is no systematic study in the literature about the factors influencing seismic risk in existing OSs. Most seismic risk assessment studies focus mainly on building, structure, and infrastructure performances.

Considering OSs as one of the components influencing the risk in a BE, the present paper addresses the seismic risk assessment in existing OSs in BEs, aiming at defining risk factors for its evaluation related to specific risk factors, e.g., morphology and typology, the geometry of the space, materials and paving, uses and users of the surrounding buildings over time, and accessibility condition. Risk factors represent key thematic aspects of the seismic risk assessment in the existing OSs in a BE. They are herein defined as macrocategories in which a variety of risk factors, defined as specific features of the OS, are collected. Using a systematic review process $[33,34]$, it was possible to gain a broad insight into how studies are currently facing the evaluation of the risk factors of urban OSs. The systematization of the results has the following objectives:

- Accomplishing a critical state-of-the-art based on a comprehensive literature review and organized by major themes deducted from the analyzed papers;

- Identifying factors influencing seismic risk in the OSs, both for LSs and ASs;

- Providing a first systematization of the risk factors identified, with the aim of a holistic characterization of seismic risk in urban OSs;

- Proposing, in this perspective, the organization of these factors in main categories to move toward a preliminary, quick, and literature-based risk index for the OS.

Starting from these results, the paper provides preliminary criteria for evaluating the seismic risk of urban OSs in emergency conditions. The methodological process of documents identification and selection is explored in Section 2. A synthesis of the review contents is presented in Section 3. A brief descriptive and bibliometric analysis of the documents involved in the review process is reported in Section 3.1, including an analysis of the trend and recurrence of thematic keywords. A report of the results organized in five thematic categories is presented in Section 3.2. Section 4 describes the systematization of the risk factors, along with their distribution analysis by authors and by thematic area. Finally, Section 5 presents the conclusions.

\section{Phases and Methods of the Systematic and Bibliographic Review}

The systematic and bibliographic screening process applied in this paper was set according to the PRISMA guideline [34] (http:/ / www.prisma-statement.org/ accessed on 
18 October 2021. The structure of the selection steps is reported in Figure 1, both for the systematic and the bibliographic process.
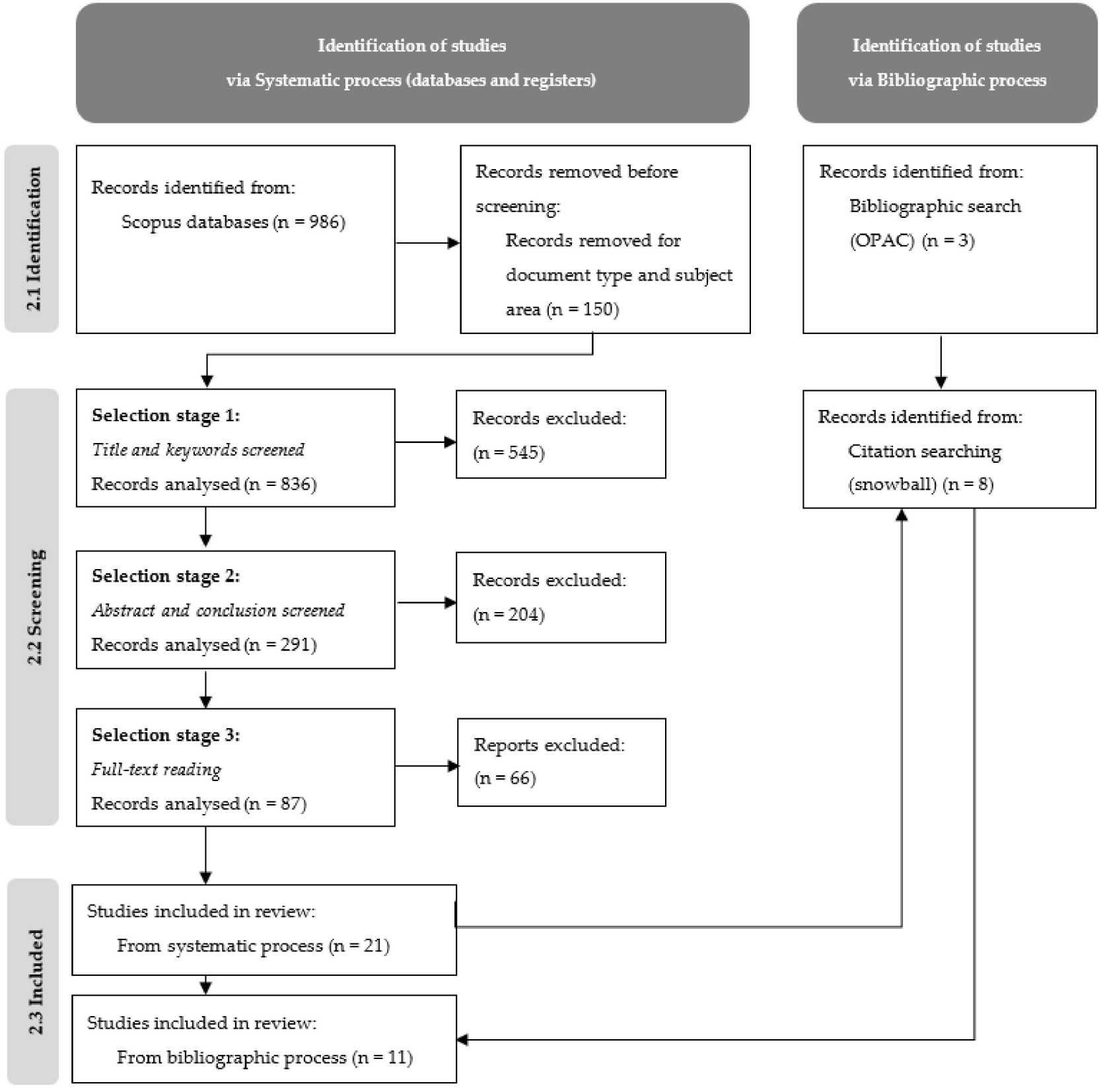

Identification of studies

via Bibliographic process

Figure 1. PRISMA flow diagram of the systematic and bibliographic methodology for the selection of documents applied in this paper (last accessed: 18 October 2021).

\subsection{Documents Identification: Search Strategy}

According to the definition of systematic review given by [33], recurring themes, approaches, and results can be recognized with the qualitative analysis and synthesis of data. Moreover, by providing a transparent and organized procedure, the process of a systematic review can be replicated efficiently [35] and reduce biases and the lack of evidence [36]. In the systematic search process, journal papers, conference paper-both peer-reviewed-and book chapters were included; grey literature (e.g., theses, preprints, working papers, technical reports) was excluded.

The search was carried out using the Scopus database (www.scopus.com; last accessed 18 October 2021). To develop an effective search strategy, the process of establishing the 
keywords to combine in a search code was iterative, and the impact in terms of the numbers and appropriateness of the results was checked.

The final keywords are summarized in Table 1. In order to represent and summarize the research question, the keywords were grouped into their respective homogeneous technical categories: risk factors, disaster type, OS, and data characterization. The search code was composed using the operator "AND" among the main columns (risk factors, disaster type, OS, data characterization) and the operator "OR" among the rows. Using an iterative process, the authors refined the keywords (Table 1). Limiting the results only to the English language and filtering documents for "subject area" (eliminate: immunology and microbiology, pharmacology, toxicology and pharmaceutics, health professions, economics, econometrics and finance, and nursing) and "document type" (limit to: article, conference paper, book chapter, review), the total number of preliminary documents identified in the databases was 836 .

Table 1. Final keywords selected for the systematic search in Scopus.

\begin{tabular}{|c|c|c|c|c|c|}
\hline \multirow[t]{2}{*}{ Risk Factor } & \multirow[t]{2}{*}{ Disaster Type } & \multirow[t]{2}{*}{ Open Space } & \multicolumn{3}{|c|}{ Data Characterization } \\
\hline & & & $\begin{array}{c}\text { Geometry } \\
\text { and Space } \\
\text { Characteristics }\end{array}$ & $\begin{array}{l}\text { Constructive } \\
\text { Characteristics }\end{array}$ & $\begin{array}{l}\text { Use over Time } \\
\text { and Space }\end{array}$ \\
\hline Risk & Earthquake & Open space & Morphology & Construction & Pedestrian \\
\hline Vulnerability & Seismic & $\begin{array}{c}\text { Public space } \\
\text { Urban area } \\
\text { Road } \\
\text { Square } \\
\text { Park } \\
\text { Access }\end{array}$ & $\begin{array}{c}\text { Typology } \\
\text { Geometry } \\
\text { Slope } \\
\text { Underground cavities }\end{array}$ & $\begin{array}{c}\text { Pavement } \\
\text { Obstacle }\end{array}$ & $\begin{array}{l}\text { Vehicular } \\
\text { Evacuation } \\
\text { Users }\end{array}$ \\
\hline
\end{tabular}

In order to include grey literature and books suitable for this review, an expert judgment screening of these kind of publications was conducted through an online public access catalogue (OPAC).

\subsection{Documents Screening: Inclusion Criteria}

To reduce the number of studies while avoiding the loss of important contributions, the process of selection was divided into three consecutive stages. As summarized in Table 2, each stage involved a defined action and took into account different eligibility criteria, which were chosen to be appropriate in relation to the actions. The eligibility criteria encompassed the key aspects of the research question: the risk assessment as the core field of research, the earthquakes as the main disaster type, the focus on the existing $\mathrm{BE}$, the intrinsic vulnerability of OSs, and the identification of risk factors as the result.

The first selection was conducted by evaluating titles and keywords (both author and index keywords). Therefore, the eligibility of the papers was controlled by checking the global pertinence of the keywords, the research fields, the object of the case studies, and the types of disasters considered. Moreover, irrelevant documents were excluded in this first stage. The second sorting process involved the reading of the abstract and conclusions of each document previously included. In this case, the authors verified the pertinence of the objectives and the results, searching for studies which address the intrinsic risk assessment of OSs. The third stage encompassed reading the full text, to exclude those documents which do not provide any explicit risk factors definition.

To include relevant documents not identified with the described procedure, a final snowball search [37] was conducted among the references of the final studies found through the systematic process, applying the same selection criteria used for the systematic screening (Figure 1). 
Table 2. Summary of the criteria applied for the selection process.

\begin{tabular}{|c|c|c|}
\hline Selection Stage & Actions & Eligibility Criteria \\
\hline Stage 1 & Title and keywords evaluation & $\begin{array}{l}\text { Keywords: } \\
\text { global pertinence of the keywords. } \\
\text { Research fields: } \\
\text { included: risk assessment, emergency } \\
\text { management, disaster preparedness, and } \\
\text { evacuation strategies. } \\
\text { Case studies: } \\
\text { excluded: viaducts, highways, dams. } \\
\text { Disaster/hazard type: } \\
\text { included: multi-hazards studies; } \\
\text { included: earthquakes induced by other } \\
\text { hazards studies, if the effect on the OS } \\
\text { was considered (e.g., tsunami); } \\
\text { excluded: irrelevant documents. }\end{array}$ \\
\hline
\end{tabular}

\section{Objectives of research:}

excluded: risk assessment of buildings and aggregates;

included: risk assessment of monuments and historic elements.

\section{Research results:}

included: explicit definition of

\subsection{Documents Inclusion: Identification and Classification of the Final Studies Selected for} the Review

In total, 32 documents were selected for the in-depth analysis and critical review.

Table 3, 21 were identified with the systematic process and 11 were added by a traditional bibliographic method (Figure 1). The final documents were cataloged, highlighting the type of publishing source, the hazard type considered, the locations of the case studies, the risk factor involved (hazard, vulnerability, exposure), and which BE open spaces were of interest (ASs or LSs). This preliminary classification was useful to control the subject of the selected documents and to organize the following review steps.

\subsection{Bibliometric Description and Classification of Documents}

A bibliometric analysis based on the co-occurrence of the index keywords was conducted using VOSviewer software (www.vosviewer.com; version 1.6.14) [64,65], both on the documents of selection stage 1 ( 836 results) and stage 2 (291 results).

The authors imported the .ris file (Research Information Systems), downloading it from the Scopus database, selected a minimum occurrence of 10 for the keywords for the results of stage 1 and of 7 for the results of stage 2, and performed a data cleaning, both merging variants of similar terms with a thesaurus file and deleting geographical indication and a few minor terms. 
Table 3. Summary of the final documents selected for the review.

\begin{tabular}{|c|c|c|c|c|c|c|c|c|c|c|}
\hline & \multirow[t]{2}{*}{ Authors } & \multirow[t]{2}{*}{ Hazard $^{1}$} & \multirow[t]{2}{*}{ Case Study } & \multicolumn{3}{|c|}{$\begin{array}{l}\text { Identification } \\
\text { Methods }^{2}\end{array}$} & \multicolumn{4}{|c|}{ Type of Publishing Source ${ }^{3}$} \\
\hline & & & & Sy. & Sn. & Bi. & $\mathrm{J}$. & C. & B. & G.L. \\
\hline [38] & Adafer and Bensaibi (2015) & Earthquake & Ain Temouchent, Algeria & & $\mathrm{X}$ & & & $X$ & & \\
\hline [39] & Álvarez et al. (2018) & Tsunami & Iquique, Chile & & $x$ & & $x$ & & & \\
\hline [40] & Battegazzorre et al. (2021) & Earthquake & $1-1-$ & $\mathrm{X}$ & & & & $\mathrm{X}$ & & \\
\hline [23] & Bernabei et al. (2021) & Earthquake & - & $x$ & & & & $x$ & & \\
\hline [41] & Bernardini and Ferreira (2020) & Earthquake & Coimbra, Portugal & $\mathrm{X}$ & & & & $x$ & & \\
\hline [42] & Cremonini (2004) & Earthquake & - & & & $\mathrm{X}$ & & & & $\mathrm{X}$ \\
\hline [9] & D'Andrea and Condorelli (2006) & Earthquake & Catania, Italy & & & $x$ & & $\mathrm{X}$ & & \\
\hline [43] & Der Sarkissian et al. (2020) & N.H. & $\begin{array}{l}\text { Baalbek-Hermel } \\
\text { Governorate, Lebanon }\end{array}$ & $X$ & & & $\mathrm{X}$ & & & \\
\hline [44] & Ertugay et al. (2016) & Earthquake & Thessaloniki, Greece & & $\mathrm{X}$ & & $x$ & & & \\
\hline [45] & Fazzio (2004) & Earthquake & Nocera Umbra, Italy & & & $\mathrm{x}$ & & & $\mathrm{x}$ & \\
\hline [46] & Giuliani et al. (2020) & Earthquake & Lucignano, Italy & $x$ & & & $X$ & & & \\
\hline [47] & Goretti and Sarli (2006) & Earthquake & Potenza, Italy & & $\mathrm{X}$ & & $x$ & & & \\
\hline [48] & Hajibabaee et al. (2014) & Earthquake & Tehran, Iran & $x$ & & & $x$ & & & \\
\hline [49] & Ito et al. (2021) & Tsunami & $\begin{array}{l}\text { Zihuatanejo, Guerrero, } \\
\text { Mexico }\end{array}$ & $x$ & & & $x$ & & & \\
\hline [50] & Kanno et al. (2016) & Earthquake & $\begin{array}{l}\text { Mexico } \\
\text { Shinjuku, Tokyo, Japan }\end{array}$ & $x$ & & & $x$ & & & \\
\hline [51] & Kheliouen and Bouder (2020) & Earthquake & Boumerdés, Algiers & $x$ & & & & $\mathrm{x}$ & & \\
\hline [52] & Kumagai and Hatao (2013) & Earthquake & Neyagawa, Japan & $\mathrm{X}$ & & & & $\mathrm{X}$ & & \\
\hline [53] & Lancioni et al. (2014) & Earthquake & (20) & & $\mathrm{x}$ & & $\mathrm{X}$ & & & \\
\hline [54] & León and March (2014) & Tsunami & Talcahuano, Chile & & $x$ & & $\mathrm{X}$ & & & \\
\hline [55] & León et al. (2019) & Tsunami & Viña del Mar, Chile & & $\mathrm{X}$ & & $x$ & & & \\
\hline [24] & Lo et al. (2020) & Earthquake & Taipei City, Taiwan & $x$ & & & $\mathrm{X}$ & & & \\
\hline [29] & Quagliarini et al. (2018) & Earthquake & Offida, Italy & & $\mathrm{X}$ & & $\mathrm{X}$ & & & \\
\hline [22] & Santarelli et al. (2018) & Earthquake & Civitanova Marche, Italy & $\mathrm{X}$ & & & $x$ & & & \\
\hline [56] & Sasabe et al. (2020) & Earthquake & Nagoya, Japan & $\mathrm{X}$ & & & $x$ & & & \\
\hline [57] & Tsionas et al. (2016) & Earthquake & Thessaloniki, Greece & $\mathrm{X}$ & & & $x$ & & & \\
\hline [12] & Tumini et al. (2017) & Tsunami & $\begin{array}{l}\text { Mehuin and Dichato, } \\
\text { Chile }\end{array}$ & $x$ & & & $x$ & & & \\
\hline [58] & Utami and Nurhadi (2018) & Earthquake & Yogyakarta, Indonesia & $X$ & & & & $x$ & & \\
\hline [59] & Wang and Jia (2021) & Tsunami & $\begin{array}{l}\text { Seaside, Oregon, USA } \\
\text { Aberdeen, Hoquiam, }\end{array}$ & $X$ & & & $X$ & & & \\
\hline [60] & Wood et al. (2016) & Tsunami & $\begin{array}{l}\text { and Cosmopolis, } \\
\text { Washington, USA }\end{array}$ & $x$ & & & $x$ & & & \\
\hline [61] & Yao et al. (2021) & Earthquake & Great Victoria, Canada & $\mathrm{X}$ & & & $x$ & & & \\
\hline [62] & Zhang et al. (2015) & N.H. & Beijing, China & $\mathrm{X}$ & & & $x$ & & & \\
\hline [63] & Zlateski et al. (2020) & Earthquake & Coimbra, Portugal & $x$ & & & $\mathrm{X}$ & & & \\
\hline
\end{tabular}

${ }^{1}$ Hazard: N.H. = natural hazard in general; ${ }^{2}$ identification methods: Sy. = systematic, Sn. = snowball, Bi. $=$ bibliographic ${ }^{3}$ type of publishing source: J. = journal, C. = conference; B. = book; G.L. = grey literature.

\subsection{Collection and Analysis of the Risk Factors}

The frequency of the risk factors was retrieved by counting their related recurrences into the analyzed literature, to trace which elements seem to be more investigated by the considered works. The factors were organized into categories and examined using statistical analysis. Then, a multi criteria decision model was provided to organize the prominence of categories of risk factors into a preliminary and quick literature recurrencebased index for the risks of OSs. The analytical hierarchy process (AHP) was applied to evaluate the priorities among the retrieved documents [66]. The pairwise comparison between the categories was based on their related frequencies. We verified how many times the number of recurrences of the first category occurred in the second one by normalizing the ratios by maximum and minimum values and then scaling each ratio into the AHP scale from 1 (equally frequent) to 9 (extremely more frequent). The consistency ratio was calculated, thus verifying that the result was over the acceptability threshold of $10 \%$.

\section{Results}

\subsection{Descriptive and Bibliometric Analysis of Documents Involved in the Review Process}

According to [8], a general increase in the number of publications about the risk assessment of OSs can be observed in the last twenty-one years (Figure 2; Stage 1: 836 documents). Focusing on the contributions more related to the existing urban context (for all the selection criteria see Table 2), a similar trend can be noted in the growing rate of publications, but with a different starting point, approximately in the last decade (Stage 2: 291 documents). Despite the attention on the risk assessment of OSs being relatively recent, the graphic in 
Figure 2 clearly depicts the rising interest in the field, confirming the trend already shown by [8] for the OS resilience.

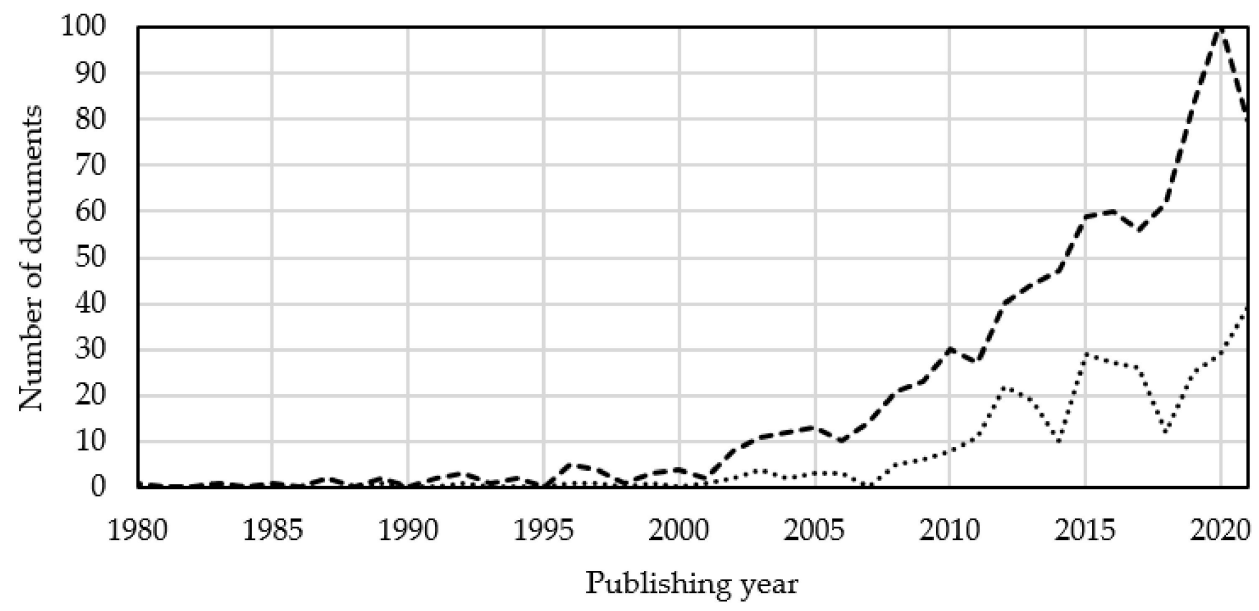

----Stage 1 [836]

Stage 2 [291]

Figure 2. Publishing years of both stage 1 (836) and stage 2 set of documents (291): 2008: 5; 2009: 6; 2010: 8; 2011: 11; 2012: 22; 2013: 19; 2014: 10; 2015: 29; 2016: 27; 2017: 26; 2018: 12; 2019: 25; 2020: 229; 2021: 39.

Referring to the bibliometric analysis based on the co-occurrence of the index keywords, Figure 3 shows that the final neural map of the stage 1 set of documents (836) includes 138 terms. The size of the circles represents the occurrence of terms; the links represent the co-occurrence. The colors identify different clusters that represent groups of keywords that are more related to each other.

In Figure 3, it is possible to observe four clusters, which show thematic grouping around different topics: the red cluster is related to buildings, structures in general, and seismology studies; the blue cluster depicts the relevance of roads/streets, evacuation, and emergency management; the green cluster identifies geological and geotechnical studies that also connect earthquakes with consequent landslide events; and the yellow cluster shows research involving the urban area as a whole, considering the correlation with tsunamis and flood risk. Observing the center of the neural map, seismic risk assessment appears to be strictly related to the vulnerability (106 occurrences) and hazard (112 occurrences) aspects of risk, while the exposure aspect is not mentioned. The main objects of the research are urban areas (78 occurrences), roads and streets (88 occurrences), and buildings (60 occurrences). Squares, parking areas, or other types of ASs do not appear in the map as main objects of research.

Considering the neural map colored by the average of the publication years, the most recent studies involve topics that have lower link strengths to the core of the neural map, such as evacuation, information management, behavioral research, the structural analysis of masonry buildings, the vulnerability assessment of urban areas, and the correlation between earthquakes and other hazards (i.e., floods, tsunamis, and fire).

For the stage 2 set of documents, the final neural map includes 73 terms (Figure 4). The six clusters identified highlight some interesting topics, which also emerged during the review process. The red and green clusters point out the crucial role of the infrastructures (roads/streets, bridges, and transportation network) in the emergency management, response, and evacuation strategies; simulations, structural analysis, and fragility curves stand out as main tools. The purple cluster represents a group of studies in which earthquakes are connected to tsunamis and floods, in a multi-hazard prospective. The green and purple clusters are adjacent to the light blue one, which includes GIS systems and remote sensing, showing the close correlation among these tools to the seismic risk as- 
sessment involving OSs, especially LSs. The yellow cluster represents terms related to hazards, landslides, the evaluation of debris, and the geotechnical aspects of the seismic risk assessment. Lastly, the blue cluster groups the terms in relation to cities, e.g., damage detection, computational methods, and surveys are the most frequent tools linked.

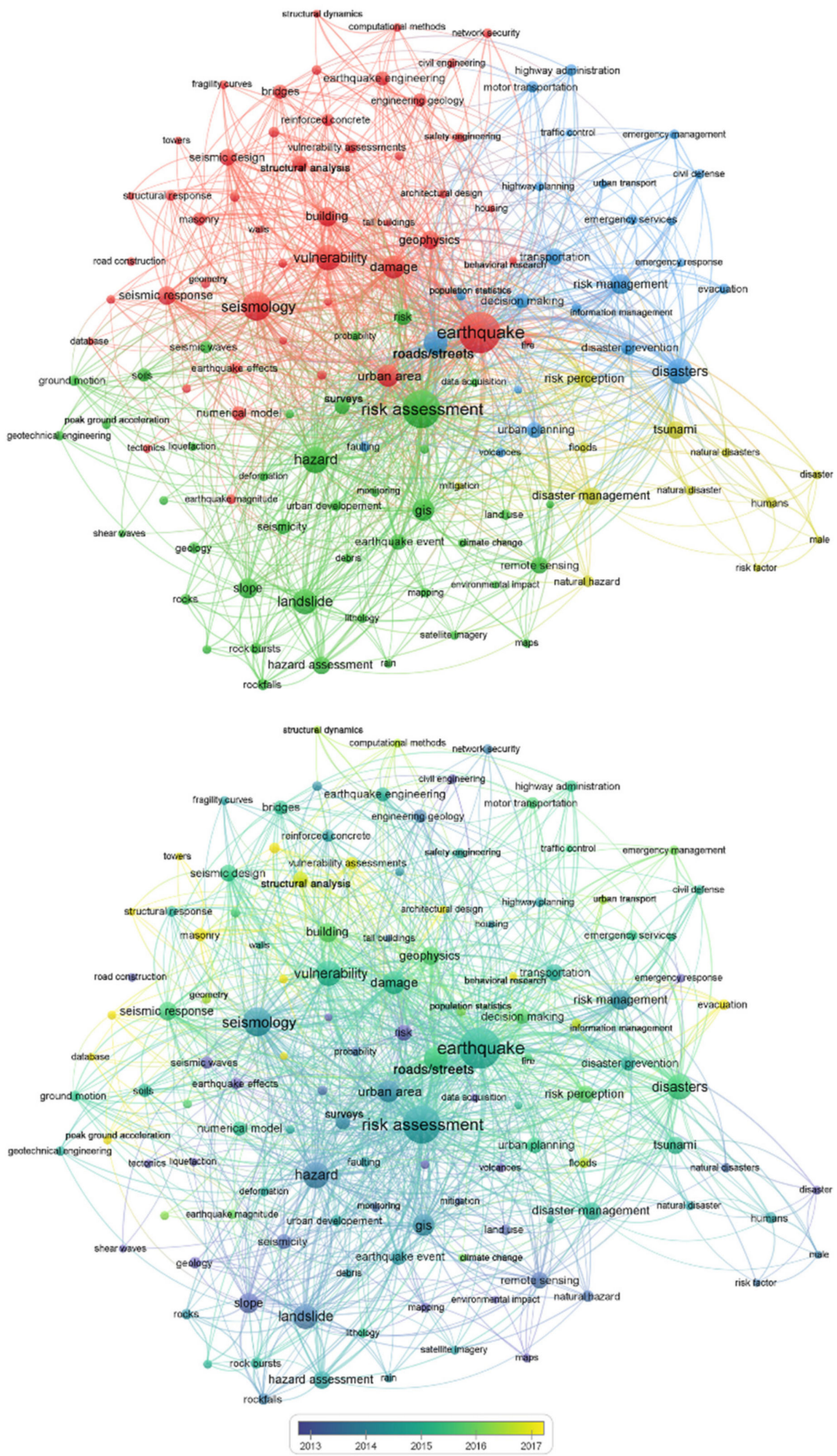

Figure 3. Neural map of the Scopus index keywords' recurrence in the set of documents of stage 1 (836 papers), realized with VOSviewer: colored by clusters (above) and publication years (below). 


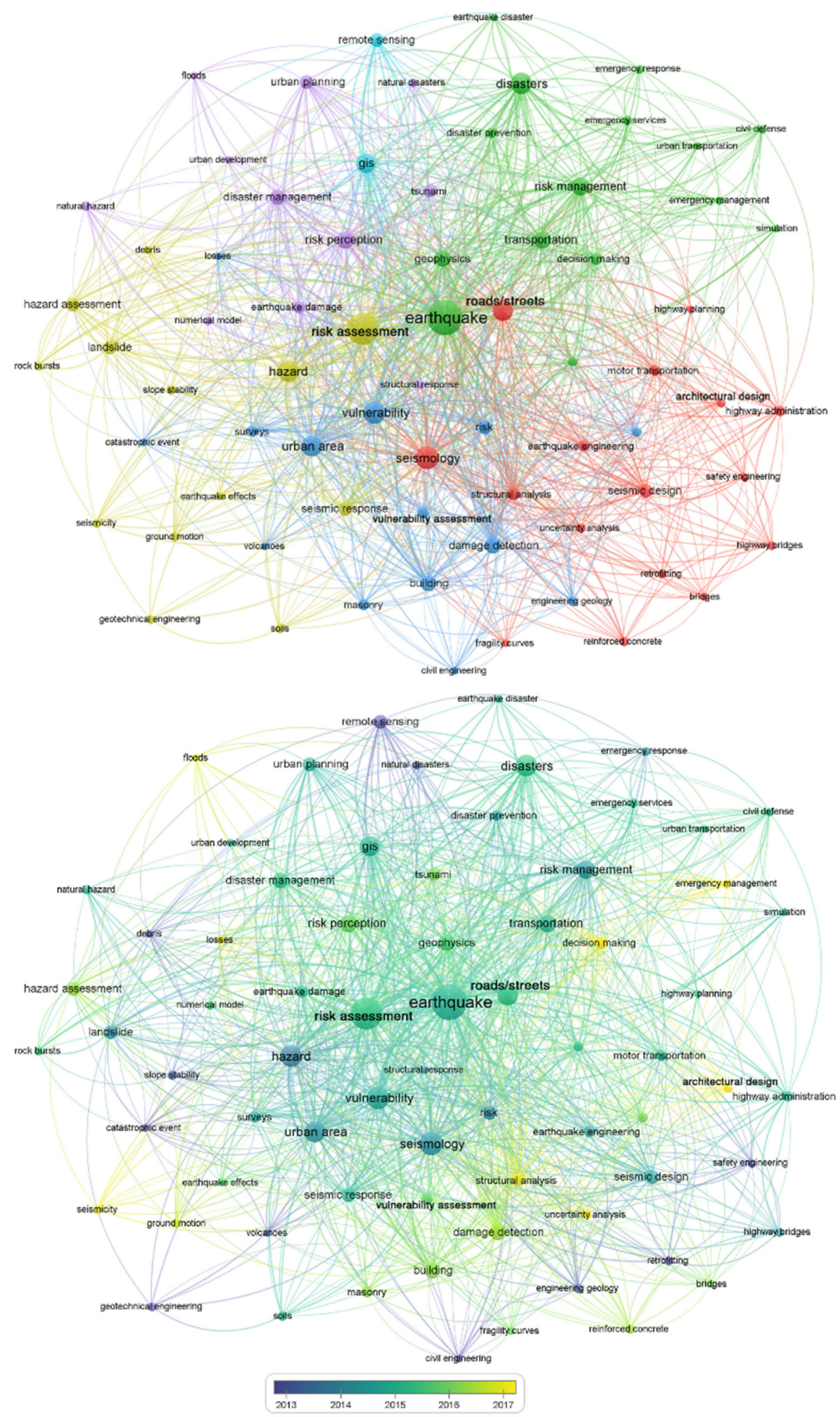

Figure 4. Neural map of the Scopus keywords' recurrence in the set of documents of stage 2 (291 papers), realized using VOSviewer: colored by clusters (above) and by publication years (below).

The neural map colored by the average of the publication years detected recent subject terms that have lower link strengths to the core of the map, such as fragility curves, structural analysis, uncertainty analysis, simulation, and GIS, showing a growing tendency towards analytical studies. 
The final set of documents selected for the review process were analyzed for their publishing sources-the 32 papers are distributed as follows: 23 from journals, 7 from conferences, 1 from books, and 1 from grey literature.

\subsection{Analysis of the Final Selected Documents and the Synthesis of the Results}

It was possible to group the several recurring risk factors found from the literature review (Appendix A) by identifying five categories useful for the classification and analysis of the results. The category of "morpho-typological characteristics" gathers the factors related to the morphological and typological classification of urban systems; the category of "physical characteristics" identifies the geometric and dimensional features of the OS and its main elements; the factors included in the "constructive characteristics" category highlight the constructive aspects of the OS; the category of "characteristics of use" describe the space occupation (temporal and spatial) and the functions of the OS (usual or temporary); and the "characteristics of context" category defines the context in which the OS is located from a geological, infrastructural, and multi-hazard point of view.

According to the five categories, the factors are organized as follow and are discussed in their corresponding sections:

- Morpho-typological characteristics (Section 3.2.1): morpho-typology of the space, dimensions of the OS, number of lanes of LS;

- Physical characteristics (Section 3.2.2): quote difference of the OS, slope of the OS, slope near the OS, fixed obstacles, temporary obstacles;

- Constructive characteristics (Section 3.2.3): paving type, paving conditions;

- Characteristics of use and users (Section 3.2.4): presence of parked vehicles, accessibility for vehicles/pedestrians, types of users, density of users, preparedness of users;

- Characteristics of context (Section 3.2.5): seismicity, multi-hazard potential, ground type, lifeline utilities, urban OSs network, underground cavities.

\subsubsection{Morpho-Typological Characteristics}

The morpho-typological characteristics of the OS are a key factor for the risk assessment of the BE. The analysis of the urban context morphology is essential since it has an implication on the functionality of the general infrastructure system, in particular on the street network vulnerability [42,45].

Some morpho-typological analyses consider the whole OS in the urban area, applying the space syntax approach proposed by Hillier [67] with various techniques. These studies evaluate the spatial configuration of the OS network as being composed of nodes and links $[46,56]$, with the aim of establishing the relationship between the different parts of network structures and identifying high-risk paths in the OS urban system [50]. Moreover, some studies express additional indicators to characterize the overall urban OS typology. Among them, [12] includes the relation between unbuilt and built areas (the "balance index"), the roads redundancy (the evacuation route index), and the roads connectivity (the walkability index), while [29] introduce a classification by location type (level path/square, hillside, in a tunnel, on a bridge). Other morpho-typological analyses deal with the local scale, supporting comparisons between different urban paths in terms of their ability to allow a smooth pedestrian evacuation. Among studies that propose typological indexes, it is possible to find the "pedestrian route directness index", defined as the ratio between a route's actual distance throughout urban space and the geodetic (or straight-line) distance between its origin and destination [54,55]; the "road resistor coefficient", defined as the ratio between road length and the road width [62]; the path "tortuosity index", defined as the difference between the minimum linear path length and the average evacuees' path length [41]; and the "difference-in-path ratio", that expresses the ratio between the effective evacuation path length and the ideal one [63].

The dimensions of the OSs are assessed considering their width, length, and area. Many studies examine the OS's width in relation with the height of the building facing it, considering the risk of debris formation on the road after a seismic event $[9,22,23,40-42,47,48,52,57,63]$. 
Others recognize the role of the OS width for the estimation of the potential pedestrian evacuation flow $[51,58,62]$, sometimes also considering the interfering obstacles (e.g., urban furniture), that could limit the effective width of the paths and consequently the evacuation speed $[29,39,54]$ (see also Section 3.2.2), or the sudden narrowing of the OS [45,57]. The literature shows how the OS's length has a relation to the access and smooth movement of the emergency services, evaluating both the ante- and post-event scenarios [24,46], and with the time required for pedestrian evacuees to reach a safe destination $[12,29,50]$. Moreover, it is also possible to use the overall OS length to compare different urban areas, using the street network density index, defined as the ratio between the total length of streets within a sector and the sector's overall area [55]. Lastly, the OS's area has a particular role in estimating the ability of ASs (e.g., squares, parking) to be used as secure spaces [29,61]. The "temporary secure OSs" index expresses the ratio between the total area of secure OSs and the number of evacuees [12].

The number of lanes should be considered as one of the risk factors identified in the literature, as it is particularly useful to analyze the LSs [38]. Although it could be considered similar to the aforementioned dimensions of the OSs, it is particularly useful in expeditious studies to classify a large number of LSs in relation to the escape capacity [54] or to assess the presence of the single/double direction of traffic travel [29], crucial for both the provision of emergency services and the assessment pedestrian escape flow. In this sense, this index should also be correlated to the "evacuation route distance" describing the maximum Euclidean path length [12] and be used to identify the riskiest conditions for pedestrians due to their exposure time while moving. The "effective areas surface" index describes similar conditions referring to the OSs' area and the debris presence due to building debris, which can affect both the evacuation process and the users' possibility to remain in nonovercrowded conditions while waiting for the rescuers' arrival [63], thus being combined in the "temporary secure OSs" index. Table 4 lists the above-mentioned indices.

\subsubsection{Physical Characteristics}

The section on the physical characteristics of the OSs primarily includes the discussion around the micro-vulnerability of the $\mathrm{BE}$, which can reduce the capacity of an efficient evacuation $[39,55]$. It can be considered a micro-vulnerability amongst all the factors influencing the pedestrian flow and the access for emergency services during the evacuation process, in terms of speed and safety.

The quote difference of the OS (e.g., stairs or steps) and the slope of the OS (i.e., the inclination of the OS itself) can be considered a factor influencing the overall urban vulnerability $[45,57]$. In particular, they affect the patterns of people's movement, especially of the vulnerable categories [46], their speed [39,55,60], and the access to safe ASs, both for pedestrians and vehicles [42].

The slope near the OS factor describes the possibility of having a sloping ground condition on the frontier of the OS, which, potentially becoming unstable after a seismic event, can have a detrimental effect on the OS $[29,38,45,58,60]$.

Among the fixed and temporary obstacles, all the elements of urban furniture that can produce an obstruction to smooth evacuation should be considered [39]. Fixed obstacles could include trees, fences, signboards, poles, canals, and low walls [22,29,55,58]; temporary obstacles may include street vendors, kiosks, garbage bins, and restaurant areas (i.e., dehors) [55]. From a long-term assessment point of view, the provisional structures that secure the buildings' façades should also be considered as temporary obstacles, since they reduce the movement of vehicles along the road [47]. Table 5 lists the above-mentioned index. 
Table 4. Risk factors related to the morpho-typological characteristics and related indices, proposed or cited in the analyzed literature.

\begin{tabular}{|c|c|c|c|}
\hline Factor & & Index & Definition \\
\hline \multirow{5}{*}{ Morpho-typology } & {$[12]$} & Balance & $\begin{array}{l}\text { Ratio between the overall surface } \\
\text { of the unbuilt useful ASs and the } \\
\text { overall surface of the built areas }\end{array}$ \\
\hline & {$[55]$} & Pedestrian route directness & $\begin{array}{l}\text { Ratio between a route's actual } \\
\text { distance throughout urban space } \\
\text { and the geodetic (or straight-line) } \\
\text { distance between its origin } \\
\text { and destination }\end{array}$ \\
\hline & {$[62]$} & Road resistor coefficient & $\begin{array}{l}\text { Ratio between the road length and } \\
\text { the road width }\end{array}$ \\
\hline & {$[41]$} & Tortuosity & $\begin{array}{l}\text { difference between the minimum } \\
\text { linear path length and the average } \\
\text { evacuees' path length }\end{array}$ \\
\hline & {$[63]$} & Difference-in-path ratio & $\begin{array}{l}\text { Ratio between the effective } \\
\text { evacuation path length and the } \\
\text { ideal one }\end{array}$ \\
\hline \multirow{3}{*}{ Dimension of the OSs } & \multirow{2}{*}[12]{} & Temporary secure OSs & $\begin{array}{c}\text { Ratio between the overall surface } \\
\text { of the temporary secure ASs and } \\
\text { the number of inhabitants in the } \\
\text { same area }\end{array}$ \\
\hline & & Evacuation route distances & $\begin{array}{l}\text { Distance of evacuation routes } \\
\text { from the farthest point in } \\
\text { Euclidean distance }\end{array}$ \\
\hline & {$[63]$} & Effective areas surface & $\begin{array}{l}\text { Difference between the OS area } \\
\text { and the area occupied by debris }\end{array}$ \\
\hline
\end{tabular}

Table 5. Risk factors related to the physical characteristics and related indices, proposed or cited in the analyzed literature.

\begin{tabular}{ccc}
\hline Factor & Index & Definition \\
\hline Temporary obstacles & {$[39]$} & $\begin{array}{c}\text { Impact of the } \\
\text { micro-vulnerabilities } \\
\text { along the evacuation } \\
\text { path on the evacuation } \\
\text { speed }\end{array}$ \\
\hline
\end{tabular}

\subsubsection{Constructive Characteristics}

The constructive characteristics of the OS aim to describe the type and condition of the OS pavement, which affect the intrinsic vulnerability of the BE.

Paving type includes its characterization in terms of materials (e.g., asphalt, tiled), finishing (e.g., smooth, rough), and laying (e.g., compact or not). It could be useful for the comparison of a huge variety of LSs [38], in order to assess the accessibility [29] and the maximum speed of the evacuees $[39,55]$, which are especially affected by slippery surfaces [46].

Paving condition refers to both maintenance and the post-event damage state. The maintenance (e.g., cracked roads) affects the safety of the evacuation [38], influencing people's speed [55] and the potential of pedestrian injuries during the escape [29]. After the event, the condition of the pavements can change due to the fall of elements related to the context $[54,55]$ and the soil liquefaction phenomena, which can cause a permanent ground deformation $[24,44,56]$. These events can damage the pavements, resulting in a slowdown of the emergency operations and/or an interruption of a part of the OS network [59].

\subsubsection{Characteristics of Use and Users}

The characteristics of the use and users of the OS collect the features related to the functions of the OS and the type of people present in it, which affect the risk in the OS in terms of exposure. 
The presence of parked vehicles along the LSs and ASs is included among the OS functions that have an impact on its safety [45]. Both legal and illegal parking spots should be mapped to have a comprehensive awareness of the urban OS uses [62]. Parked vehicles occupy part of the LSs, reducing the available width of the evacuation paths and affecting the road risk for pedestrian evacuation $[29,39,54,55,62]$. Moreover, the location of the parking spots should also be evaluated to assess their accessibility during the post-event phase, when a combined pedestrian/vehicular evacuation could be carried out [59].

The accessibility for vehicles/pedestrians describes the exclusive use or not of the OS, which notably affects the type and speed of evacuation flow after a disastrous event $[42,59]$ or the possibility of being reached by emergency services [61]. Different types of flows along the same LS during the evacuation phase have an impact on the risk for pedestrians, especially considering the different mental state of the drivers compared to ordinary days $[57,62]$ or the possibility of having multi-directional movements in the same OS, especially in the ASs [29]. Pedestrian-only evacuation paths are strongly recommended [9,49]. Where it is not possible to grant this condition, a "walkability index" should be considered to assess the percentage of pedestrian streets and walkways separated from roads for vehicles [12]. Moreover, if part of the roadway is occupied by the vehicular flow or a traffic jam, the speed of the evacuation can be compromised; the "pedestrian speed conservation index" has been proposed to evaluate the percentage of speed loss of the evacuation flow [54,55].

Different types of users affect many aspects of the immediate post-event phase, among them the response capacity and rescue operations [46], since differences in age $[48,49,60]$, in physical condition $[41,54,55,59]$, and in local knowledge of the place (e.g., residents vs tourists or occasional visitors) $[23,42]$ can have an impact on the speed and efficiency of the evacuation flow. It could also be useful to compare the night and day distribution of the population, to highlight the worst possible scenario [55].

The density of the users influences the safety and the effectiveness of the evacuation flow [9]. It is possible to find many approaches in the literature to estimate in advance the expected evacuees' density. Some of them consider a static amount of people, including only the residents in the count [12,48,52]; others add at least the employees of business activities and/or the tourist flow facing the OS considered [40,49,60,63]; finally, more indepth studies consider the concentration variation along different times of the day (e.g., the daily movement of the users) [9,23], the week (e.g., weekday, weekend) [23,61], or the year (e.g., seasonal use of property, touristic flows) [59]. The density could be approximated on a semi-quantitative basis [29], using a demographic database [46] or by comparing the ordinary situation with the evacuation demand [56]. The density of the users can also influence the behavior of the people. In the case of high crowding, some people could choose a longer evacuation path that is less dense of evacuees [50] or try to move against the evacuation stream to find their relatives [62].

The preparedness of users describes the level of formation of both the competent authorities and the local users. The literature shows how having clear information about the best evacuation path and the location of safe places can support a smooth evacuation process [60], especially if training exercises have been organized [48]. People aware of the vulnerability of the area can have a role in triggering the evacuation and leading other evacuees [49]. The ability to have an efficient and prompt response should also be supported with adequate emergency response planning and evacuation management strategies $[12,48,63]$. Table 6 lists the above-mentioned indices. 
Table 6. Risk factors related to the characteristics of use and users and related indices, proposed or cited in the analyzed literature.

\begin{tabular}{|c|c|c|c|}
\hline Factor & & Index & Definition \\
\hline \multirow[t]{2}{*}{$\begin{array}{c}\text { Accessibility for } \\
\text { vehicles/pedestrians }\end{array}$} & [12] & Walkability & $\begin{array}{l}\text { Ratio between the } \\
\text { pedestrian walkway } \\
\text { length and the total } \\
\text { street length }\end{array}$ \\
\hline & [54] & $\begin{array}{l}\text { Pedestrian speed } \\
\text { conservation }\end{array}$ & $\begin{array}{c}\text { percentage of evacuees' } \\
\text { speed loss }\end{array}$ \\
\hline Type of users & [59] & $\begin{array}{l}\text { Walking speed } \\
\text { variability }\end{array}$ & $\begin{array}{l}\text { Adjustment in the } \\
\text { walking speed due to } \\
\text { age and } \\
\text { physical condition }\end{array}$ \\
\hline \multirow{4}{*}{ Density of users } & [23] & $\begin{array}{l}\text { Daytime, night-time, } \\
\text { holiday time exposure }\end{array}$ & $\begin{array}{l}\text { Evaluated as the sum of } \\
\text { exposure for the outdoor } \\
\text { and indoor areas for } \\
\text { different times (daytime, } \\
\text { night, holiday) }\end{array}$ \\
\hline & {$[12,48]$} & Population density & $\begin{array}{c}\text { Ratio between the total } \\
\text { inhabitant and the } \\
\text { urban area }\end{array}$ \\
\hline & {$[50]$} & Congestion degree & $\begin{array}{l}\text { calculation of } \\
\text { the crowding } \\
\text { condition along } \\
\text { evacuation paths }\end{array}$ \\
\hline & {$[63]$} & Occupancy & $\begin{array}{l}\text { Calculation of the } \\
\text { crowding condition in } \\
\text { the OS, considering the } \\
\text { area reduction due to } \\
\text { debris }\end{array}$ \\
\hline
\end{tabular}

\subsubsection{Characteristics of Context}

The section on the characteristics of the context includes factors that connect the analyzed BE with more general aspects of the surrounding area, which can affect the overall safety of a specific OS.

The seismicity is among the pivotal factors that influence the seismic local vulnerability of the BE and the OSs $[38,45,53]$, primarily important for a complete evaluation of the vulnerability of LSs identified as evacuation paths [9] or ASs as safe areas [61]. A seismic hazard could be evaluated qualitatively by adopting the values of the seismic zonation, if available, or quantitatively using the peak ground acceleration [22-24,29,40,43,48,63].

The multi-hazard potential considers the possibility that a second event can occur due to the first (with a correlation, e.g., landslide, tsunami, fire) or simply after (without a correlation, e.g., flood), worsening the effects and limiting the availability of LSs as evacuation paths [42] or ASs as temporary safe areas [61]. Some research considers scenarios where a second disaster is induced by the earthquake (e.g., landslide, slope instability, subsidence of river embankment), producing unexpected damages or obstructions along the evacuation path $[9,29,38,60]$. Among these cases, the loss of function of the electrical and water pipes can also be included, which can generate a cascade effect $[29,48]$, or the direct damages on the BE induced by a tsunami [59]. The ground type describes the soil typology and topography of the surrounding area. The material which the soil is made of (e.g., hard or soft) and the soil stratification influence the propagation frequency of the seismic waves $[38,53,61]$. To assess this risk, the topographic amplification factor can be included in the risk evaluation [29]. Local vulnerability scenarios should include evaluations on the location of the $\mathrm{BE}$ with respect to the geomorphology of the territory (e.g., ridge or edge area, area with poor-quality soil) [42] and assess the risk of soil liquefaction [24,48,56,61].

The lifeline utilities include all the entities that provide essential infrastructure services to the community, i.e., water, wastewater, transport, energy, and telecommunications. Loss of resiliency of part of them can compromise the overall infrastructure after a disastrous event $[42,48]$. Damages to the lifeline utilities can create obstacles in the evacuation 
path, falling on the OSs (e.g., electric wires) $[42,54]$ or locally damaging the surface of pavement [29].

The urban OSs network considers the relation between each OS and the system to which it belongs, recognizing the connectivity among the OSs as one of the vulnerability factors of them $[12,22,29,42,51,58,62,63]$. It can be evaluated qualitatively, through morphotypological analysis (e.g., regular or irregular geometry), or quantitatively, using metric computation and more complete indicators capable of estimating the specific features of urban OSs networks, such as robustness, steadiness, and accessibility. The vulnerability of a specific OS could be influenced by the loss of functionality of part of its network (e.g., a link or node interruption or blockage). It is possible to assess the connectivity resilience of OSs network using the "flow robustness indicator", defined as the ratio of the number of available flows (before and after the event) to the total number of possible flows in a network [43], or evaluating the steadiness of the spatial properties with configurationalbased indices, such as the "mean connectivity" and "frequency" indices [46]. Although a general "evacuation route" index [12] can be used to take into account the overall and homogeneous distribution of inhabitants among the evacuation routes, local damages to buildings and roads can affect the accessibility of urban OSs network as well [47,59]. Some evacuation paths may no longer be available, increasing the density of the evacuees along other evacuation paths ("congestion degree index") [50] or the distance that evacuees should cover [52]. A "connectivity index", defined as the ratio between the street links (i.e., street sections between intersections) and the street nodes (i.e., intersections), could be useful to evaluate how accessible a OSs network is and if it enables short evacuations [55].

The presence of natural or human-made underground cavities (e.g., caves, cisterns, artificial underground structures) has an impact on the overall risk of urban OSs, since their position and dimension influence the frequency spectrum amplification of seismic waves [53]. Moreover, they could provoke local instability and cause damages or collapse to the LSs [29]. Table 7 lists the above-mentioned indices.

Table 7. Risk factors related to the characteristics of context and related indices, proposed or cited in the analyzed literature.

\begin{tabular}{|c|c|c|c|}
\hline Factor & & Index & Definition \\
\hline \multirow{6}{*}{ Urban OSs network } & {$[43]$} & Flow robustness & $\begin{array}{l}\text { Ratio between the number of } \\
\text { available flow and the total } \\
\text { number of the possible flow in } \\
\text { the network }\end{array}$ \\
\hline & & Mean connectivity & $\begin{array}{l}\text { Ratio between the connectivity } \\
\text { values and the total number of } \\
\text { segments }\end{array}$ \\
\hline & {$[46]$} & Frequency & $\begin{array}{l}\text { Ratio between the maximum } \\
\text { actual choice in the set of } \\
\text { segments and the maximum } \\
\text { value it could virtually reach }\end{array}$ \\
\hline & {$[12]$} & Evacuation route & $\begin{array}{l}\text { between the number of } \\
\text { evacuation paths and the } \\
\text { overall inhabitants }\end{array}$ \\
\hline & {$[50]$} & Congestion degree & $\begin{array}{l}\text { Calculation of the crowd along } \\
\text { evacuation paths }\end{array}$ \\
\hline & {$[55]$} & Connectivity & $\begin{array}{l}\text { Ratio between street links and } \\
\text { street nodes }\end{array}$ \\
\hline
\end{tabular}




\section{Discussion}

The distribution of the risk factors found in the analyzed literature by category (Table A1) is summarized in Figure 5. The characteristics of context category records the highest number of occurrences (50), followed by the characteristics of use and users (49) and the morpho-typological characteristics (39), all three being above the mean values (35.0). The physical characteristics (24) and the constructive characteristics (13) show values lower than the mean, suggesting more evaluations should be conducted on these two aspects of risk.

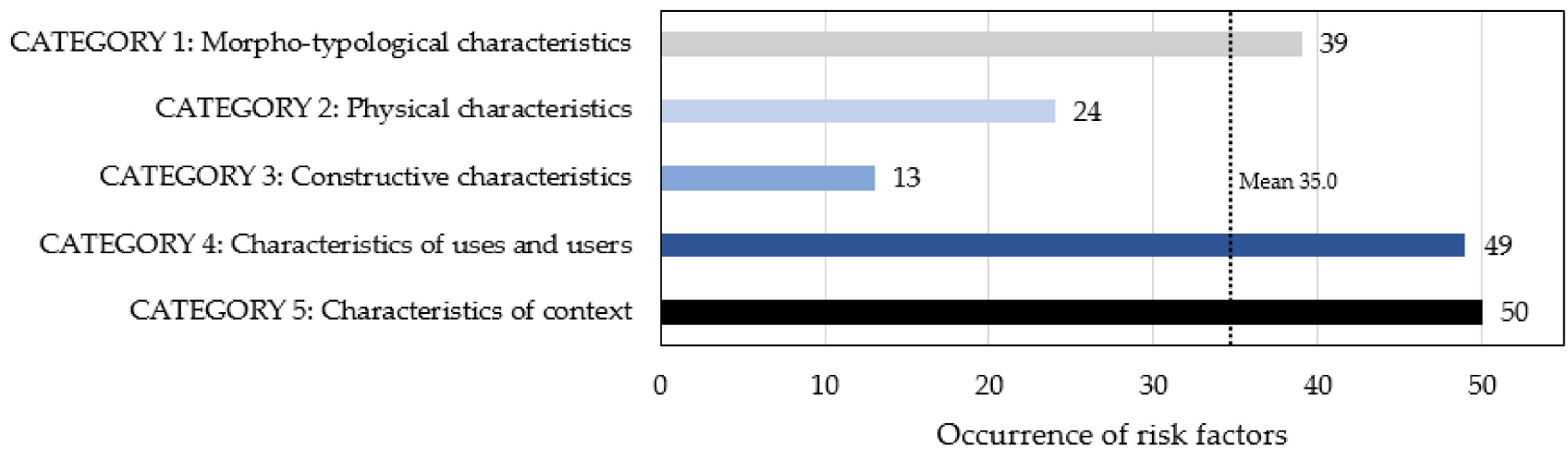

Figure 5. Distribution of the risk factors in the analyzed literature listed by categories. The values on the $\mathrm{x}$ axis indicate the total occurrences of the risk factors in each category.

Comparing the overall occurrence of the risk factors with the mean occurrence in each category (Figure 6), it is possible to highlight their influence in the current literature. In Category 1, the dimension of OS is the most recurring aspect with 24 occurrencesscoring strongly above the mean value-while morpho-typology is just below the mean with 12 occurrences. This category shows higher mean values compared to the others, indicating that morpho-typological studies are one of the research areas currently most connected to the risk assessment of OSs. The distribution of Category 2 is rather uniform, with a slight prevalence of the slope of the OS with 6 occurrences. The low mean value of this category compared to the others highlights micro-vulnerability as one of the most promising research areas for further research. In particular, the evaluation of the temporary obstacles along the LSs and into the ASs should be included in the next studies. In Category 3 , the paving condition records 8 occurrences, while the paving type has 5 . The potentially wide variety of the paving that it is possible to have, especially in the ASs, suggests that more studies should evaluate the effect of the typology and quality of the paving on the risk in the OSs. In Category 4, the density of users shows the higher occurrence (17), while the preparedness of users records has a lower occurrence (5), strongly below the mean values, highlighting this aspect as a significant research line to explore. In Category 5, the urban OSs network (15) and the seismicity (13) show values clearly above the mean, while the lifeline utilities (4) and the underground cavities (2) appear to be of minor importance, although further research should verify the real impact of these factors. The multi-hazard potential and the ground-type (8) have an occurrence in line with the mean value, nevertheless with a high impact on the risk implications.

The distribution of the risk factors by authors shows the correlation between the categories considered (Figures 7-9). 


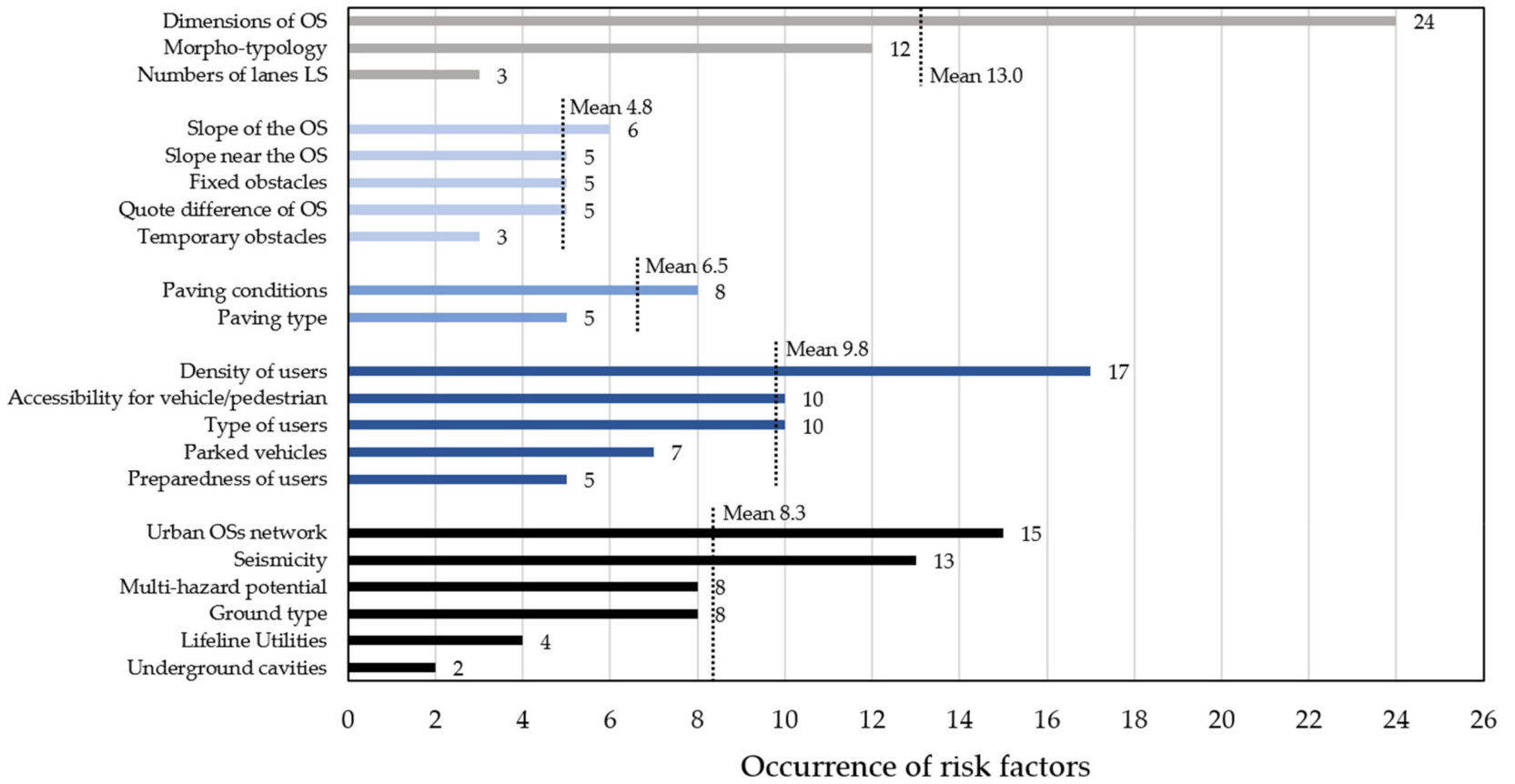

Figure 6. Distribution of the risk factors in the analyzed literature. The values on the $x$ axis indicate the total occurrences of each risk factor.

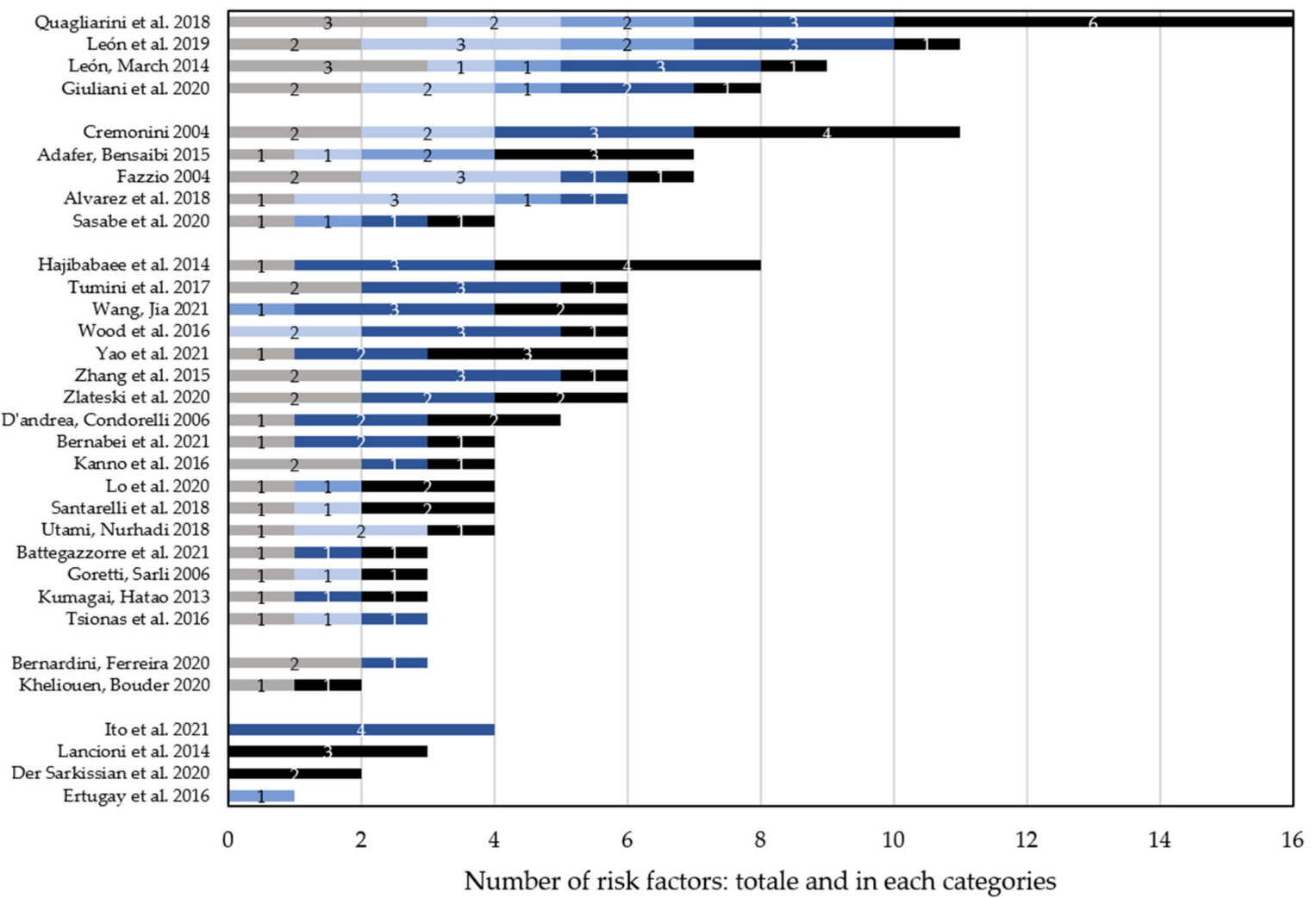

Figure 7. Distribution of risk factors in the analyzed literature listed by authors. The values on the $x$ axis indicate the occurrences of the factors into each category. 


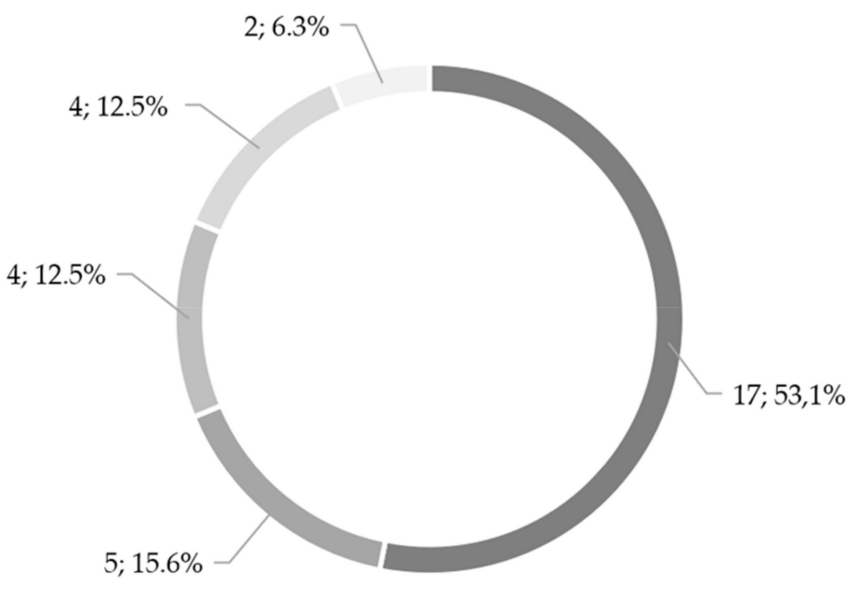

\author{
- Three categories $[17 ; 53.1 \%]$ \\ = Four categories $[15 ; 15.6 \%]$ \\ ॥ Five categories $[4 ; 12.5 \%]$ \\ One category $[4 ; 12.5 \%]$ \\ Two categories $[2 ; 6.3 \%]$
}

Figure 8. Number and percentage of studies involving risk factors that belong to different categories.

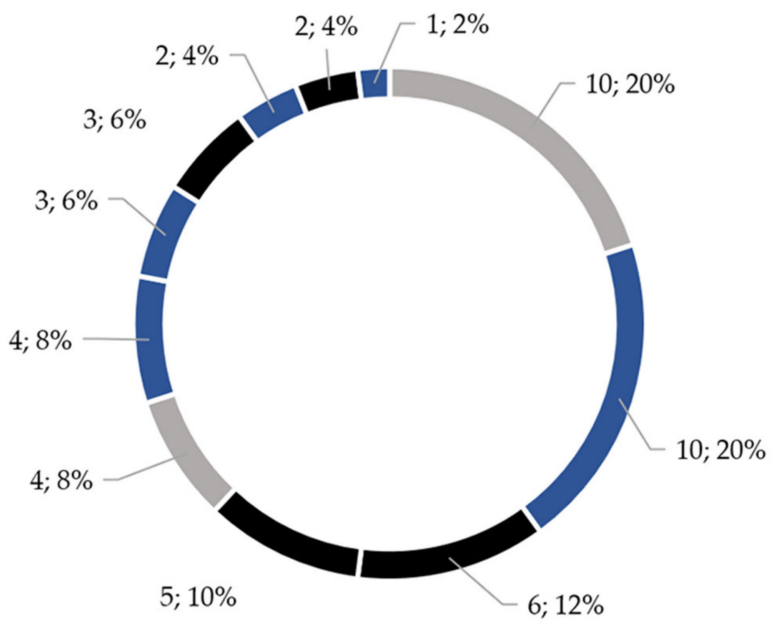

— Dimensions of OS [10; 20\%]
- Density of users $[10 ; 20 \%]$
- Seismicity $[6 ; 12 \%]$
- Urban OSs network $[5 ; 10 \%]$
- Morpho-typology $[4 ; 8 \%]$
- Accessibility for vehicle/pedestrian $[4 ; 8 \%]$
- Preparedness of users $[3 ; 6 \%]$
- Multi-hazard potential $[3 ; 6 \%]$
- Type of users $[2 ; 4 \%]$
- Ground type $[2 ; 4 \%]$

Figure 9. Occurrence and percentage of the risk factors in studies that involve three categories. The colors indicate the category to which the parameters belong.

Of the 32 papers analyzed, 17 consider factors that belong to three categories $(53.1 \%)$, 5 to four categories $(15.6 \%), 4$ to five categories $(12.5 \%), 4$ to one category $(12.5 \%)$, and 2 to two categories (6.3\%) (Figure 8). As Figure 7 shows, factors included in the characteristics of context are often taken into account as the main topics of monothematic studies. Among those, the seismicity is the most frequent factor included in the research. Considering the studies that include factors from three categories, a recurrent combination is represented by morpho-typological characteristics, the characteristics of use, and characteristics of context, that recurs 10 times in the 17 studies (Figure 7). Among those, considerations of the dimensions of the OSs $(10 ; 20 \%)$, density of users $(10 ; 20 \%)$, and seismicity $(6 ; 12 \%)$ are the most frequent, covering over $50 \%$ of the total. Conversely, in Category 4 the risk factors which are included less are parked vehicles $(4 ; 8 \%)$, types of users $(4 ; 8 \%)$, preparedness of users $(4 ; 8 \%)$, and accessibility for vehicles/pedestrians $(4 ; 8 \%)$; in Category 5 , they are ground type $(2 ; 4 \%)$ and multi-hazard potential $(3 ; 6 \%)$ (Figure 9$)$.

The Figure 10 shows the counting of documents including risk factors that belong to each category. From the total amount of 32 papers, 27 consider factors listed in Category 5, 26 in Category 1, 23 in Category 4, 13 in Category 2, and 10 in Category 3. According to such recurrences, Table 8 displays the priorities for each of these categories according to the AHP application. 


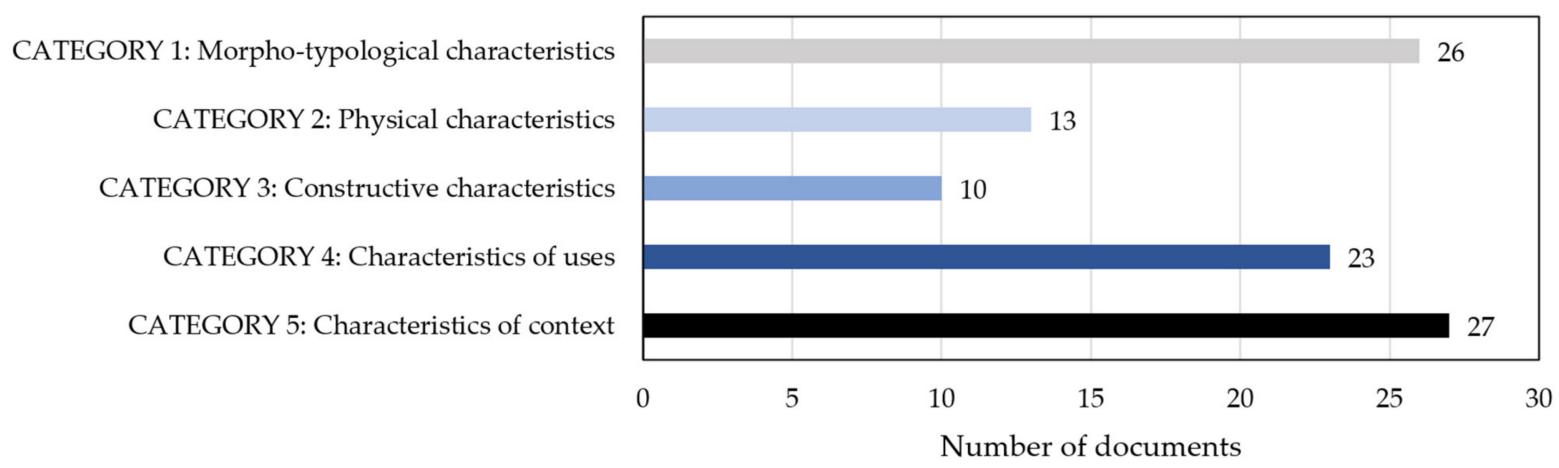

Figure 10. Number of documents including risk factors that belongs to each category, from the total of 32 document analyzed in the review.

Table 8. Priority of the categories of risk factors according to the AHP application.

\begin{tabular}{cccccc}
\hline Category & (1) Morpho-typological & (2) Physical & (3) Constructive & (4) Uses and Users & (5) Context \\
\hline Weight & $31.4 \%$ & $4.9 \%$ & $2.8 \%$ & $19.3 \%$ & $41.5 \%$ \\
\hline
\end{tabular}

The complete calculation values are included in the AHP.csv file in the Supplementary Materials (Table S1). The consistency ratio of the AHP is acceptable since it is equal to $6.6 \%<10 \%$. The greater the weights, the greater the availability of assessment methodologies, and the greater the reliability of performing analyses on the considered categories. In this sense, the proposed index can also support designers and non-expert stakeholders in risk assessment. Designers could perform specific evaluations for each category. Then, the evaluation results could be weighted by the related AHP priority values in Table 8, thus linearly combining them to describe the overall risk of the OS. Categories affected by a more limited availability of evaluation methodologies will have a lower impact on the OS risk. Therefore, a conservative standpoint in the risk assessment is pursued, since the index tries to limit uncertainties under such circumstances (e.g., data availability to apply the methodology; level of knowledge on the effective risk factors affecting the OS risk).

\section{Conclusions}

The importance of the open spaces (OSs) in the existing built environment (BE) is critical for the overall safety of the urban context and its users against seismic events. Since the risk assessment of the OSs is strictly related to the BE components, a broad evaluation of the different aspects that characterize the $\mathrm{BE}$ is of significant importance.

A systematic and bibliographic literature review on the intrinsic factors influencing the seismic risk of the existing OSs and the safety of their users was presented and analyzed in the present paper. The nature of the documents involved in the review process was investigated using a quantitative trend and correlation analysis and described using neural maps. From the final 32 publications selected for the in-depth review, 21 risk factors were identified. Five categories were highlighted, each one representing peculiar characteristics of the OSs in relation to seismic risk assessment: the morpho-typological characteristics, physical characteristics, constructive characteristics, characteristics of use and users, and characteristics of context.

The systematization of the whole factors in the five categories gave a qualitative overlook of the different aspects that affect urban OS safety during an emergency condition. A quantitative statistical analysis was conducted on the factors identified through the indepth review. According to the defined categories of risk factors, this analysis also allowed a preliminary and quick literature-based index for the risks of the OSs to be outlined, which relied on the availability of previous existing methodologies. The impact of each category of risk factors was assessed according to an analytical hierarchy process approach, and the calculations showed its theoretical effectiveness. Hence, future works should try to apply 
the index to real-world OSs to define its reliability. Since the index is based on weighted categories, further activities should try to include the effect of each factor. In particular, the discussion shows some aspects for enhancing further research, including the importance of considering factors that belong to all five categories, currently a minority of the total final papers, and the consolidating role of some factors (e.g., the dimension of the OS, the morpho-typology of the space, the density of users, the urban OS network, and the seismicity), highly recurring in the literature compared to others, whose role should be explored in future research (e.g., the fixed and temporary obstacles, the paving type and condition, the preparedness of users, the multi-hazard potential, the lifeline utilities, and the underground cavities).

The results of the present paper can support the definition of strategies for improving the safety standard of the existing BE, providing a holistic view of the seismic risk in the OSs. Moreover, the identification of specific features of the OSs affects the overall safety of the $\mathrm{BE}$ in that it allows stakeholders to evaluate, plan, and prioritize projects at the micro- and meso-scale with a high impact on the urban scale. Also considering the improvement of the resilience of the $\mathrm{BE}$, the paper contributes and supports the transition between a prevention phase to a preparation phase. Additional studies should be conducted to verify and deepen the results highlighted in the present paper. Nevertheless, these results represent a necessary first step towards the global characterization and modeling of Oss in a digital environment, to accomplish simulations and define more efficient mitigation strategies.

Supplementary Materials: The following are available online at https:/ / www.mdpi.com/article/10 $.3390 /$ su14010042/s1. Table S1: AHP calculation values.

Author Contributions: Conceptualization of the research, E.C., M.R., M.A. and E.Q.; conceptualization of the paper, M.R. and M.A.; methodology, M.R., M.A. and E.C.; systematic review investigation, M.R. and M.A.; bibliometric analysis software, M.R.; AHP analysis, G.B.; systematic review process validation, M.R., M.A. and L.S.; statistical analysis, M.R.; data curation, M.R. and M.A.; writingoriginal draft preparation, M.R. (Sections 2, 3.1, 3.2, 4 and 5), M.A. (Sections 1, 3.1, 4 and 5), and G.B. (Sections 2.5 and 4); writing-review and editing, M.R., M.A., G.B., L.S. and E.C.; visualization, M.R.; supervision, E.C.; project administration, E.C., G.B. and E.Q.; funding acquisition, E.C. and E.Q. All authors have read and agreed to the published version of the manuscript.

Funding: This research was funded by the MIUR (the Italian Ministry of Education, University, and Research) Project BE S2ECURe-(make) Built Environment Safer in Slow and Emergency Conditions through behavioUral assessed/designed REsilient solutions (Grant number: 2017LR75XK).

Institutional Review Board Statement: Not applicable.

Informed Consent Statement: Not applicable.

Data Availability Statement: The data presented in this study are available online on the website of the Project BE S2ECURe: Available online: https:/ / en.bes2ecure.net/ https:/ / en.bes2ecure.net/wp3 (accessed on 20 December 2021).

Conflicts of Interest: The authors declare no conflict of interest. 


\section{Appendix A}

Table A1. Summary of the whole factors influencing the intrinsic seismic risk of the OSs found in literature and grouped by the five categories identified by the authors.

\begin{tabular}{|c|c|c|c|c|c|c|c|c|c|c|c|c|c|c|c|c|c|c|c|c|c|c|}
\hline Cit & Authors & & $\begin{array}{l}\overrightarrow{1} \\
\overrightarrow{0} \\
\dot{0} \\
\stackrel{0}{0} \\
0\end{array}$ & & & & 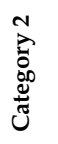 & & & co & & & & 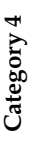 & & & & & 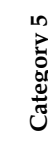 & & & \\
\hline & & & 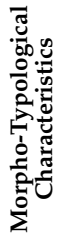 & & & & 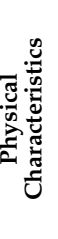 & & & 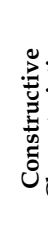 & & & & 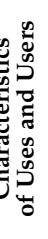 & & & & & 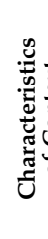 & & & \\
\hline & & 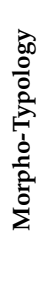 & 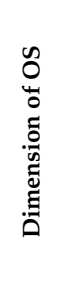 & 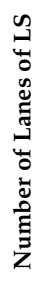 & 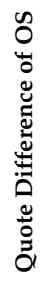 & 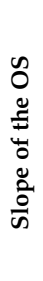 & 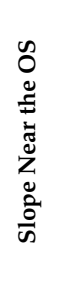 & 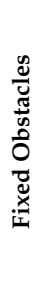 & 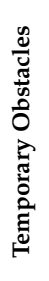 & 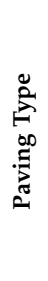 & 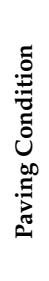 & 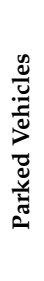 & 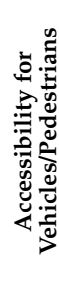 & 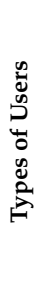 & 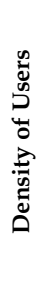 & 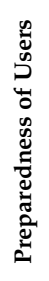 & 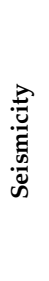 & 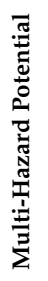 & 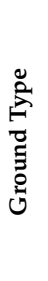 & 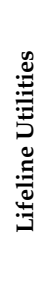 & 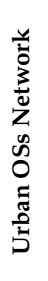 & 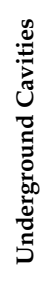 \\
\hline [38] & Adafer and Bensaibi (2015) & & & $x$ & & & $x$ & & & $x$ & $x$ & & & & & & $x$ & $x$ & $x$ & & & \\
\hline [39] & Álvarez et al. (2018) & & $x$ & & $X$ & & & $X$ & $\mathrm{x}$ & $\mathrm{X}$ & & $X$ & & & & & & & & & & \\
\hline [40] & Battegazzorre et al. (2021) & & $x$ & & & & & & & & & & & & $x$ & & $\mathrm{x}$ & & & & & \\
\hline [23] & Bernabei et al. (2021) & & $x$ & & & & & & & & & & & $X$ & $x$ & & $x$ & & & & & \\
\hline [41] & Bernardini and Ferreira (2020) & $x$ & $x$ & & & & & & & & & & & $X$ & & & & & & & & \\
\hline [42] & Cremonini (2004) & $x$ & $\mathrm{X}$ & & $x$ & $X$ & & & & & & & $\mathrm{X}$ & $\mathrm{X}$ & $x$ & & & $X$ & $\mathrm{X}$ & $\mathrm{X}$ & $x$ & \\
\hline [9] & D'Andrea and Condorelli (2006) & & $x$ & & & & & & & & & & $x$ & & $x$ & & $\mathrm{x}$ & $x$ & & & & \\
\hline [43] & Der Sarkissian et al. (2020) & & & & & & & & & & & & & & & & $x$ & & & & $x$ & \\
\hline [44] & Ertugay et al. (2016) & & & & & & & & & & $X$ & & & & & & & & & & & \\
\hline [45] & Fazzio (2004) & $x$ & $\mathrm{X}$ & & $\mathrm{X}$ & $\mathrm{X}$ & $x$ & & & & & $x$ & & & & & $x$ & & & & & \\
\hline [46] & Giuliani et al. (2020) & $x$ & $\mathrm{X}$ & & $x$ & $\mathrm{x}$ & & & & $X$ & & & & $\mathrm{X}$ & $X$ & & & & & & $x$ & \\
\hline$[47]$ & Goretti and Sarli (2006) & & $x$ & & & & & & $x$ & & & & & & & & & & & & $x$ & \\
\hline$[48]$ & Hajibabaee et al. (2014) & & $x$ & & & & & & & & & & & $X$ & $X$ & $X$ & $x$ & $x$ & $x$ & $x$ & & \\
\hline [49] & Ito et al. 2021 & & & & & & & & & & & & $\mathrm{X}$ & $\mathrm{X}$ & $\mathrm{X}$ & $x$ & & & & & & \\
\hline [50] & $\begin{array}{l}\text { Kanno et al. (2016) } \\
\text { Kheliouen }\end{array}$ & $x$ & $x$ & & & & & & & & & & & & $x$ & & & & & & $x$ & \\
\hline [51] & Kheliouen, Bouder (2020) & & $\mathrm{X}$ & & & & & & & & & & & & & & & & & & $x$ & \\
\hline$[52]$ & $\begin{array}{c}\text { Kumagai and Hatao (2013) } \\
\text { Lancioni et al. (2014) }\end{array}$ & & $x$ & & & & & & & & & & & & $X$ & & & & & & $x$ & \\
\hline$[53]$ & $\begin{array}{l}\text { Lancioni et al. (2014) } \\
\text { León and March (2014) }\end{array}$ & $\gamma$ & & $\mathrm{x}$ & & $x$ & & & & & & & & & & & $\mathrm{X}$ & & $\mathrm{X}$ & $x$ & & $X$ \\
\hline$[55]$ & $\begin{array}{l}\text { León and March (2014) } \\
\text { León et al. (2019) }\end{array}$ & $\begin{array}{l}X \\
X\end{array}$ & $\begin{array}{l}X \\
X\end{array}$ & $x$ & $x$ & $X$ & & $x$ & $x$ & $x$ & $\begin{array}{l}X \\
X\end{array}$ & $\begin{array}{l}X \\
X\end{array}$ & $\begin{array}{l}X \\
x\end{array}$ & $\begin{array}{l}X \\
X\end{array}$ & & & & & & $X$ & $x$ & \\
\hline [24] & Lo et al. (2020) & & $\hat{x}$ & & & & & & & & $\hat{x}$ & & & & & & $\mathrm{x}$ & & $\mathrm{x}$ & & & \\
\hline [29] & Quagliarini et al. (2018) & $x$ & $\hat{x}$ & $\mathrm{x}$ & & & $x$ & $x$ & & $x$ & $\hat{X}$ & $x$ & $x$ & & $\mathrm{X}$ & & $\hat{x}$ & $\mathrm{X}$ & $x$ & $x$ & $x$ & $\mathrm{x}$ \\
\hline [22] & Santarelli et al. (2018) & & $x$ & & & & & $x$ & & & & & & & & & $x$ & & & & $x$ & \\
\hline [56] & Sasabe et al. (2020) & $\mathrm{x}$ & & & & & & & & & $x$ & & & & $x$ & & & & $x$ & & & \\
\hline [57] & Tsionas et al. (2016) & & $X$ & & & $x$ & & & & & & & $x$ & & & & & & & & & \\
\hline [12] & Tumini et al. (2017) & $x$ & $X$ & & & & & & & & & & $x$ & & $x$ & $\mathrm{X}$ & & & & & $x$ & \\
\hline [58] & Utami and Nurhadi (2018) & & $x$ & & & & $x$ & $x$ & & & & & & & & & & & & & $x$ & \\
\hline [59] & Wang and Jia (2021) & & & & & & & & & & $X$ & $X$ & & $x$ & $\mathrm{X}$ & & & $\mathrm{X}$ & & & $\mathrm{X}$ & \\
\hline [60] & Wood et al. (2016) & & & & & $x$ & $X$ & & & & & & & $\mathrm{X}$ & $x$ & $\mathrm{X}$ & & $x$ & & & & \\
\hline [61] & Yao et al. (2021) & & $\mathrm{X}$ & & & & & & & & & & $\mathrm{X}$ & & $x$ & & $\mathrm{x}$ & $\mathrm{X}$ & $x$ & & & \\
\hline [62] & Zhang et al. (2015) & $x$ & $X$ & & & & & & & & & $X$ & $x$ & & $x$ & & & & & & $X$ & \\
\hline [63] & Zlateski et al. (2020) & $x$ & $x$ & & & & & & & & & & & & $x$ & $x$ & $x$ & & & & $x$ & \\
\hline
\end{tabular}

\section{References}

1. Haigh, R.; Amaratunga, D. An integrative review of the built environment discipline's role in the development of society's resilience to disasters. Int. J. Disaster Resil. Built Environ. 2010, 1, 11-24. [CrossRef]

2. Quagliarini, E.; Currà, E.; Fatiguso, F.; Mochi, G.; Salvalai, G. Resilient and User-Centered Solutions for a Safer Built Environment against Sudden and Slow Onset Disasters: The BE S2ECURe Project. In Sustainability in Energy and Buildings 2020. Smart Innovation, Systems and Technologies; Littlewood, J., Howlett, R.J., Jain, L.C., Eds.; Springer: Singapore, 2021; Volume 203.

3. Pereira, L.V. Urban Form Definition in Urban Planning; LNEC: Lisbon, Portugal, 1982.

4. Russo, M.; Angelosanti, M.; Bernardini, G.; Cantatore, E.; D'Amico, A.; Currà, E.; Fatiguso, F.; Mochi, G.; Quagliarini, E. Morphological Systems of Open Spaces in Built Environment Prone to Sudden-Onset Disasters. In Sustainability in Energy and Buildings 2020 (Part of the Smart Innovation, Systems and Technologies Book Series-SIST, Volume 203-ISSN: 2190-3018); Littlewood, J., Howlett, R.J., Jain, L.C., Eds.; Springer: Singapore, 2021; pp. 321-331. ISBN 978-981-15-8783-2.

5. Strappa, G. L'architettura Come Processo; Franco Angeli: Milan, Italy, 2014. 
6. Currà, E.; D'Amico, A.; Nettekoven, M. Seismic vulnerability and urban morphology, tools for urban and building integration. In City as Organism New Visions for Urban Life; Strappa, G., Amato, A.R.D., Camporeale, A., Eds.; U+D Edition: Roma, Italy, 2016; Volume 1, pp. 473-484. ISBN 978-88-941188-1-0.

7. Allan, P.; Bryant, M.; Wirsching, C.; Garcia, D.; Teresa Rodriguez, M. The Influence of Urban Morphology on the Resilience of Cities Following an Earthquake. J. Urban Des. 2013, 18, 242-262. [CrossRef]

8. Koren, D.; Rus, K. The potential of open space for enhancing urban seismic resilience: A literature review. Sustainability 2019, 11, 5942. [CrossRef]

9. D'Andrea, A.; Condorelli, A. Metodologie e procedure per la valutazione del rischio sismico sulle infrastrutture varie. In Proceedings of the XXV Convegno Nazionale Stradale, Napoli, Italy, 4-7 October 2006; pp. 78-91.

10. Costa, C.; Figueiredo, R.; Silva, V.; Bazzurro, P. Application of open tools and datasets to probabilistic modeling of road traffic disruptions due to earthquake damage. Earthq. Eng. Struct. Dyn. 2020, 49, 1236-1255. [CrossRef]

11. Cutter, S.L. Vulnerability to environmental hazards. Prog. Hum. Geogr. 1996, 20, 529-539. [CrossRef]

12. Tumini, I.; Villagra-Islas, P.; Herrmann-Lunecke, G. Evaluating reconstruction effects on urban resilience: A comparison between two Chilean tsunami-prone cities. Nat. Hazards 2017, 85, 1363-1392. [CrossRef]

13. Angelosanti, M.; Bernabei, L.; Russo, M.; D'Amico, A.; Bernardini, G.; Cantatore, E.; Fatiguso, F.; Salvalai, G.; Mochi, G.; Quagliarini, E.; et al. Towards a multi-risk assessment of Open Spaces and its users: A rapid survey form to collect and manage risk factors. In Sustainability in Energy and Buildings 2021 (Part of the Smart Innovation, Systems and Technologies Book Series-SIST, Volume 263-ISSN: 2190-3018); Littlewood, J., Howlett, R.J., Jain, L.C., Eds.; Springer: Singapore, 2021 ; pp. 209-218. ISBN 978-981-16-6269-0.

14. D’Amico, A.; Russo, M.; Bernabei, L.; Angelosanti, M.; Cantatore, E.; Bernardini, G.; Fatiguso, F.; Salvalai, G.; Mochi, G.; Quagliarini, E.; et al. Verso una valutazione multi-rischio per la sicurezza dell'ambiente costruito e dei suoi utenti: Una scheda per la definizione di scenari negli spazi aperti urbani. In Proceedings of the Design and Construction Tradition and Innovation in the Practice of Architecture Progetto-Colloqui.AT.e; Sicignano, E., Ed.; EdicomEdizioni Monfalcone (Gorizia): Salerno, Italy, 2021; pp. 1508-1525.

15. Centre for Research on the Epidemiology of Disasters (CRED) EM-DAT Database. Available online: https://public.emdat.be/ (accessed on 18 October 2021).

16. Shrestha, S.R.; Sliuzas, R.; Kuffer, M. Open spaces and risk perception in post-earthquake Kathmandu city. Appl. Geogr. 2018, 93, 81-91. [CrossRef]

17. French, E.L.; Birchall, S.J.; Landman, K.; Brown, R.D. Designing public open space to support seismic resilience: A systematic review. Int. J. Disaster Risk Reduct. 2019, 34, 1-10. [CrossRef]

18. Currà, E.; Angelosanti, M.; D'Amico, A. Integrated Digital Tools for Earthquake Risk Reduction in Historic Urban Landscape of Central Italy. In Proceedings of the 4th Digital Landscape International Symposium, Nanjing, China, 25-26 October 2019.

19. Tesoriere, G. Strade, Ferrovie, Aeroporti, 5th ed.; UTET: Torino, Italy, 1991; Volume 2. ISBN 8802045410.

20. Tesoriere, G.; Marinella, G.; Russello, M. Analisi della Vulnerabilità delle Reti Stradali in Aree Soggette a Rischio Sismico. In Proceedings of the XI Società Italiana Infrastrutture Viarie (S.I.I.V.), Verona, Italy, 28-30 November 2001; p. 12.

21. Berdica, K. An introduction to road vulnerability: What has been done, is done and should be done. Transp. Policy 2002, 9 , 117-127. [CrossRef]

22. Santarelli, S.; Bernardini, G.; Quagliarini, E.; D'Orazio, M. New indices for the existing city-centers streets network reliability and availability assessment in earthquake emergency. Int. J. Archit. Herit. 2018, 12, 153-168. [CrossRef]

23. Bernabei, L.; Mochi, G.; Bernardini, G.; Quagliarini, E. Seismic risk of Open Spaces in Historic Built Environments: A matrix-based approach for emergency management and disaster response. Int. J. Disaster Risk Reduct. 2021, 65, 102552. [CrossRef]

24. Lo, I.T.; Lin, C.Y.; Yang, C.T.; Chuang, Y.J.; Lin, C.H. Assessing the Blockage Risk of Disaster-Relief Road for a Large-Scale Earthquake. KSCE J. Civ. Eng. 2020, 24, 3820-3834. [CrossRef]

25. Italian Technical Commission for Seismic Micro-Zoning. Manuale per l'analisi Della Condizione Limite per L'emergenza (CLE) Dell'insediamento Urbano; BetMultimedia: Rome, Italy, 2014.

26. Rojo, M.B.; Beck, E.; Lutoff, C. The street as an area of human exposure in an earthquake aftermath: The case of Lorca, Spain, 2011. Nat. Hazards Earth Syst. Sci. 2017, 17, 581-594. [CrossRef]

27. El-maissi, A.M.; Argyroudis, S.A.; Nazri, F.M. Seismic vulnerability assessment methodologies for roadway assets and networks: A state-of-the-art review. Sustainability 2021, 13, 61. [CrossRef]

28. Bernardini, G.; Quagliarini, E.; D'Orazio, M. Strumenti per la Gestione Dell'emergenza nei Centri Storici; EdicomEdizioni: Monfalcone, Italy, 2018. ISBN 9788896386668.

29. Quagliarini, E.; Bernardini, G.; Santarelli, S.; Lucesoli, M. Evacuation paths in historic city centres: A holistic methodology for assessing their seismic risk. Int. J. Disaster Risk Reduct. 2018, 31, 698-710. [CrossRef]

30. Spina, D.; Acunzo, G.; Fiorini, N.; Mori, F.; Dolce, M. A probabilistic simplified seismic model of masonry buildings based on ambient vibrations. Bull. Earthq. Eng. 2018, 17, 985-1007. [CrossRef]

31. Dolce, M.; Speranza, E.; Bocchi, F.; Conte, C. Structural operational efficiency indices for Emergency Limit Condition (I. OPà. CLE): Experimental results. Boll. Di Geofis. Teor. Ed Appl. 2019, 60. [CrossRef]

32. D'Amico, A. Ricostruzione post-sisma. In Strategie di Preparazione All'evento per i Centri Storici Italiani; Edicom: Monfalcone, Italy, 2021. ISBN 978-88-96386-99-6. 
33. Cumpston, M.; Li, T.; Page, M.J.; Chandler, J.; Welch, V.A.; Higgins, J.P.; Thomas, J. Cochrane Database of Systematic Reviews Updated guidance for trusted systematic reviews: A new edition of the Cochrane Handbook for Systematic Reviews of Interventions. Cochrane Database Syst. Rev. 2019, 10, ED000142. [CrossRef]

34. Page, M.J.; McKenzie, J.E.; Bossuyt, P.M.; Boutron, I.; Hoffmann, T.C.; Mulrow, C.D.; Shamseer, L.; Tetzlaff, J.M.; Akl, E.A.; Brennan, S.E.; et al. The PRISMA 2020 statement: An updated guideline for reporting systematic reviews. BMJ 2021, $372, \mathrm{n71}$. [CrossRef]

35. Palermo, T.M. New Guidelines for Publishing Review Articles in JPP: Systematic Reviews and Topical Reviews. J. Pediatr. Psychol. 2013, 38, 5-9. [CrossRef]

36. Petticrew, M.; Roberts, H. (Eds.) Systematic Reviews in the Social Sciences; Blackwell Publishing Ltd.: Oxford, UK, 2006. ISBN 9780470754887

37. Wohlin, C. Guidelines for snowballing in systematic literature studies and a replication in software engineering. In Proceedings of the ACM International Conference Proceeding Series, New York, NY, USA, 13 May 2014; pp. 1-10.

38. Adafer, S.; Bensaibi, M. Seismic Vulnerability Index for Road Networks. In Proceedings of the International Conference on Industrial Technology and Management Science (ITMS 2015), Tianjin, China, 27-28 March 2015; pp. 1233-1236.

39. Álvarez, G.; Quiroz, M.; León, J.; Cienfuegos, R. Identification and classification of urban micro-vulnerabilities in tsunami evacuation routes for the city of Iquique, Chile. Nat. Hazards Earth Syst. Sci. Discuss. 2018, 18, 2027-2039. [CrossRef]

40. Battegazzorre, E.; Bottino, A.; Domaneschi, M.; Cimellaro, G.P. IdealCity: A hybrid approach to seismic evacuation modeling. Adv. Eng. Softw. 2021, 153, 102956. [CrossRef]

41. Bernardini, G.; Ferreira, T.M. Simulating to evaluate, manage and improve earthquake resilience in historical city centers: Application to an emergency simulation-based method to the historic centre of Coimbra. Int. Arch. Photogramm. Remote Sens. Spat. Inf. Sci. 2020, 44, 651-657. [CrossRef]

42. Cremonini, I. Analisi, Valutazione e Riduzione dell'Esposizione e della Vulnerabilità Sismica dei Sistemi Urbani nei Piani Urbanistici Attuativi; Regione Emilia-Romagna Direzione Generale Programmazione Territoriale e Sistemi di Mobilità Servizio Riqualificazione Urbana: Bologna, Italy, 2004.

43. Der Sarkissian, R.; Abdallah, C.; Zaninetti, J.M.; Najem, S. Modelling intra-dependencies to assess road network resilience to natural hazards. Nat. Hazards 2020, 103, 121-137. [CrossRef]

44. Ertugay, K.; Argyroudis, S.; Düzgün, H.Ş. Accessibility modeling in earthquake case considering road closure probabilities: A case study of health and shelter service accessibility in Thessaloniki, Greece. Int. J. Disaster Risk Reduct. 2016, 17, 49-66. [CrossRef]

45. Fazzio, F. La valutazione delle vulnerabilità urbana: Il caso di Nocera Umbra. In Regione Umbria. Vulnerabilità Urbana e Prevenzione Urbanistica dEgli Effetti del Sisma: Il Caso di Nocera Umbra; Olivieri, M., Ed.; INU: Roma, Italy, 2004; pp. 88-108.

46. Giuliani, F.; De Falco, A.; Cutini, V. The role of urban configuration during disasters. A scenario-based methodology for the post-earthquake emergency management of Italian historic centres. Saf. Sci. 2020, 127, 104700. [CrossRef]

47. Goretti, A.; Sarli, V. Road network and damaged buildings in urban areas: Short and long-term interaction. Bull. Earthq. Eng. 2006, 4, 159-175. [CrossRef]

48. Hajibabaee, M.; Amini-Hosseini, K.; Ghayamghamian, M.R. Earthquake risk assessment in urban fabrics based on physical, socioeconomic and response capacity parameters (a case study: Tehran city). Nat. Hazards 2014, 74, 2229-2250. [CrossRef]

49. Ito, E.; Kosaka, T.; Hatayama, M.; Urra, L.; Mas, E.; Koshimura, S. Method to extract difficult-to-evacuate areas by using tsunami evacuation simulation and numerical analysis. Int. J. Disaster Risk Reduct. 2021, 64, 102486. [CrossRef]

50. Kanno, M.; Ehara, Y.; Hirota, M.; Yokoyama, S.; Ishikawa, H. Visualizing high-risk paths using geo-tagged social data for disaster mitigation. In Proceedings of the 9th ACM SIGSPATIAL Workshop on Location-Based Social Networks, Burlingame, CA, USA, 31 October-3 November 2016; Volume 2011. [CrossRef]

51. Kheliouen, M.Y.; Bouder, A. Improvement of the consideration of seismic risks in Algerian planning and urban development instruments: Application to the Boumerdés region (50 km east of Algiers/Algeria). E3S Web Conf. 2020, 150, 03017. [CrossRef]

52. Kumagai, K.; Hatao, K. Regional analysis of urban development based on an evacuation process in earthquake disaster situations. In Proceedings of the 13th International Conference on Computational Urban Planning and Urban Management (CUPUM 2013), Utrecht, The Netherlands, 2-5 July 2013; pp. 1-22.

53. Lancioni, G.; Bernetti, R.; Quagliarini, E.; Tonti, L. Effects of Underground Cavities on the Frequency Spectrum of Seismic Shear Waves. Adv. Civ. Eng. 2014, 2014, 1-17. [CrossRef]

54. León, J.; March, A. Urban morphology as a tool for supporting tsunami rapid resilience.A case study of Talcahuano, Chile. Habitat Int. 2014, 43, 250-262. [CrossRef]

55. León, J.; Mokrani, C.; Catalán, P.; Cienfuegos, R.; Femenías, C. The role of built environment's physical urban form in supporting rapid tsunami evacuations: Using computer-based models and real-world data as examination tools. Front. Built Environ. 2019, 4, 89. [CrossRef]

56. Sasabe, M.; Fujii, K.; Kasahara, S. Road network risk analysis considering people flow under ordinary and evacuation situations. Environ. Plan. B Urban Anal. City Sci. 2020, 47, 759-774. [CrossRef]

57. Tsionas, I.; Baltzopoulou, A.; Tsioukas, V.; Karabinis, A. Evacuation vulnerability after an urban earthquake: Mapping it using a GIS. Appl. GIS 2016, 12, 1-16. [CrossRef]

58. Utami, W.; Nurhadi, N. Evacuation Simulation for Earthquake (Case Study in Sayangan Hamlet, Kotagede Complex, Yogyakarta, Indonesia). IOP Conf. Ser. Earth Environ. Sci. 2018, 145, 012064. [CrossRef] 
59. Wang, Z.; Jia, G. A novel agent-based model for tsunami evacuation simulation and risk assessment. Nat. Hazards 2021, 105, 2045-2071. [CrossRef]

60. Wood, N.; Jones, J.; Schmidtlein, M.; Schelling, J.; Frazier, T. Pedestrian flow-path modeling to support tsunami evacuation and disaster relief planning in the U.S. Pacific Northwest. Int. J. Disaster Risk Reduct. 2016, 18, 41-55. [CrossRef]

61. Yao, Y.; Zhang, Y.; Yao, T.; Wong, K.; Tsou, J.Y.; Zhang, Y. A GIS-Based System for Spatial-Temporal Availability Evaluation of the Open Spaces Used as Emergency Shelters: The Case of Victoria, British Columbia, Canada. Int. J. Geo Inf. 2021, 10, 63. [CrossRef]

62. Zhang, N.; Huang, H.; Su, B.; Zhao, J. Analysis of dynamic road risk for pedestrian evacuation. Phys. A Stat. Mech. Appl. 2015, 430, 171-183. [CrossRef]

63. Zlateski, A.; Lucesoli, M.; Bernardini, G.; Ferreira, T.M. Integrating human behaviour and building vulnerability for the assessment and mitigation of seismic risk in historic centres: Proposal of a holistic human-centred simulation-based approach. Int. J. Disaster Risk Reduct. 2020, 43, 101392. [CrossRef]

64. Van Eck, N.J.; Waltman, L. VOSviewer Manual. Available online: https://www.vosviewer.com/documentation/Manual_ VOSviewer_1.6.8.pdf (accessed on 18 October 2021).

65. Van Eck, N.J.; Waltman, L. VOS: A new method for visualizing similarities between objects. In Proceedings of the Studies in Classification, Data Analysis, and Knowledge Organization; Springer: Berlin/Heidelberg, Germany, 2007; pp. $299-306$.

66. Saaty, T.L. The Analytic Hierarchy Process: Planning Setting Priorities, Resource Allocation; McGraw-Hill: New York, NY, USA, 1980.

67. Hillier, B.; Hanson, J. The Social Logic of Space; Cambridge University Press: Cambridge, UK, 1984. ISBN 9780521233651. 